\title{
Four new taraxastane-type triterpenoic acids from
}

\author{
Cirsium setosum
}

\section{Electronic Supplementary Information}

Na Luan ${ }^{\mathrm{a} 1}$, Wen-Di Wei ${ }^{\mathrm{a}}$, Ali Wang ${ }^{\mathrm{a}}$, Xiu-Li Wu ${ }^{\mathrm{b}}$, Yan Qi ${ }^{\mathrm{c}}$, Jin-Jie Li ${ }^{\mathrm{a}}$, Jian-Quan Zheng ${ }^{\mathrm{a}}$, Xiao-Ya

$$
\text { Shang }^{\mathrm{a}^{*}}
$$

${ }^{a}$ Beijing Key Laboratory of Bioactive Substances and Functional Foods, Beijing Union University, Beijing 100191, China;

${ }^{b}$ College of Pharmacy, Ningxia Medical University, Yinchuan 750004, China;

${ }^{c}$ Beijing Municipal Bureau of City Administration and Law Enforcement, Beijing 101500, China.

*Corresponding author. E-mail: shangxiaoya@ buu.edu.cn. (X.Y. Shang)

${ }^{1}$ These authors contributed equally to this work 


\section{The List of Contents}

\begin{tabular}{|c|c|c|}
\hline No. & Contents & Page \\
\hline 1 & The HRESIMS Spectrum of Compound $\mathbf{1}$ & $\mathbf{S 4}$ \\
\hline 2 & The IR Spectrum of Compound $\mathbf{1}$ & S5 \\
\hline 3 & The ${ }^{1} \mathrm{H}$ NMR Spectrum of Compound $\mathbf{1}$ in Pyr & S6 \\
\hline 4 & The ${ }^{13} \mathrm{C}$ NMR Spectrum of Compound $\mathbf{1}$ in $\mathrm{Pyr}$ & S7 \\
\hline 5 & The DEPT Spectrum of Compound $\mathbf{1}$ in Pyr & S8-9 \\
\hline 6 & The ${ }^{1} \mathrm{H}-{ }^{1} \mathrm{H}$ COSY Spectrum of Compound $1 \mathrm{Pyr}$ & S10 \\
\hline 7 & The HSQC Spectrum of Compound $\mathbf{1}$ in Pyr & S11 \\
\hline 8 & The HMBC Spectrum of Compound $\mathbf{1}$ in Pyr & S12 \\
\hline 9 & The ROESY Spectrum of Compound $\mathbf{1}$ in Pyr & S13 \\
\hline 10 & The HRESIMS Spectrum of Compound 2 & S14 \\
\hline 11 & The IR Spectrum of Compound 2 & S15 \\
\hline 12 & The ${ }^{1} \mathrm{H}$ NMR Spectrum of Compound 2 in Pyr & S16 \\
\hline 13 & The ${ }^{13} \mathrm{C}$ NMR Spectrum of Compound 2 in Pyr & S17 \\
\hline 14 & The DEPT Spectrum of Compound 2 in Pyr & S18-19 \\
\hline 15 & The ${ }^{1} \mathrm{H}^{1}{ }^{1} \mathrm{H}$ COSY Spectrum of Compound $2 \mathrm{Pyr}$ & $\mathbf{S 2 0}$ \\
\hline 16 & The HSQC Spectrum of Compound 2 in Pyr & $\mathbf{S 2 1}$ \\
\hline 17 & The HMBC Spectrum of Compound 2 in Pyr & $\mathbf{S} 22$ \\
\hline 18 & The ROESY Spectrum of Compound 2 in Pyr & $\mathbf{S 2 3}$ \\
\hline 19 & The HRESIMS Spectrum of Compound $\mathbf{3}$ & $\mathbf{S 2 4}$ \\
\hline 20 & The IR Spectrum of Compound $\mathbf{3}$ & $\mathbf{S} 25$ \\
\hline 21 & The ${ }^{1} \mathrm{H}$ NMR Spectrum of Compound 3 in Pyr & $\mathbf{S 2 6}$ \\
\hline 22 & The ${ }^{13} \mathrm{C}$ NMR Spectrum of Compound 3 in Pyr & S27 \\
\hline
\end{tabular}




\begin{tabular}{|c|l|l|}
\hline $\mathbf{2 3}$ & The DEPT Spectrum of Compound $\mathbf{3}$ in Pyr & $\mathbf{S 2 8 - 2 9}$ \\
\hline $\mathbf{2 4}$ & The ${ }^{1} \mathrm{H}^{1}{ }^{1} \mathrm{H}$ COSY Spectrum of Compound $\mathbf{3}$ Pyr & $\mathbf{S 3 0}$ \\
\hline $\mathbf{2 5}$ & The HSQC Spectrum of Compound $\mathbf{3}$ in Pyr & $\mathbf{S 3 1}$ \\
\hline $\mathbf{2 6}$ & The HMBC Spectrum of Compound $\mathbf{3}$ in Pyr & $\mathbf{S 3 2}$ \\
\hline $\mathbf{2 7}$ & The ROESY Spectrum of Compound $\mathbf{3}$ in Pyr & $\mathbf{S 3 3}$ \\
\hline $\mathbf{2 8}$ & The HRESIMS Spectrum of Compound $\mathbf{4}$ & $\mathbf{S 3 4}$ \\
\hline $\mathbf{2 9}$ & The IR Spectrum of Compound $\mathbf{4}$ & $\mathbf{S 3 5}$ \\
\hline $\mathbf{3 0}$ & The ${ }^{1}$ H NMR Spectrum of Compound $\mathbf{4}$ in Pyr & $\mathbf{S 3 6}$ \\
\hline $\mathbf{3 1}$ & The ${ }^{13}$ C NMR Spectrum of Compound $\mathbf{4}$ in Pyr & $\mathbf{S 3 7}$ \\
\hline $\mathbf{3 2}$ & The DEPT Spectrum of Compound $\mathbf{4}$ in Pyr & $\mathbf{S 3 8 - 3 9}$ \\
\hline $\mathbf{3 3}$ & The ${ }^{1}$ H- ${ }^{1}$ H COSY Spectrum of Compound $\mathbf{4}$ Pyr & $\mathbf{S 4 0}$ \\
\hline $\mathbf{3 4}$ & The HSQC Spectrum of Compound $\mathbf{4}$ in Pyr & $\mathbf{S 4 1}$ \\
\hline $\mathbf{3 6}$ & The HMBC Spectrum of Compound $\mathbf{4}$ in Pyr & $\mathbf{S 4 3}$ \\
\hline
\end{tabular}




\section{Single Mass Analysis (displaying only valid results)}

\section{Tolerance $=10.0$ PPM / DBE: $\min =-2.0, \max =40.0$}

Selected filters: None

\section{Monoisotopic Mass, Odd and Even Electron Ions}

32 formula(e) evaluated with 1 results within limits (up to 50 best isotopic matches for each mass)

Elements Used:
C: $0-500$ H: $0-1000$
0: $0-4$

XJ-59-HREI 19 (1.014) Cn (Cen,5, 30.00, Ht); Sm (Mn, 2×3.00); Cm (18:19)

Autospec

100 466.9728

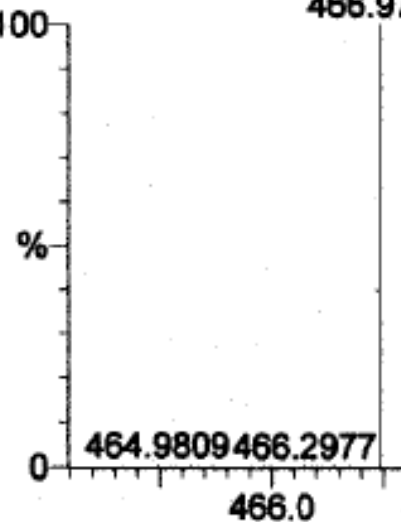

466.0
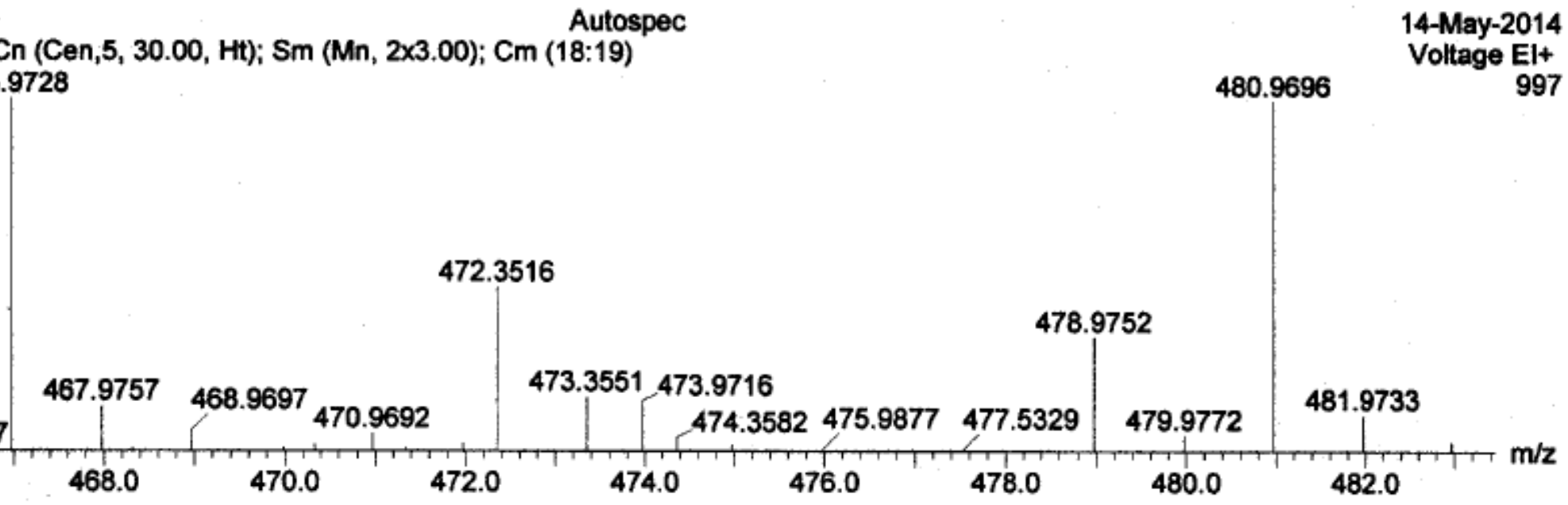

\section{Minimum:}

Maximum:

$\begin{array}{lll}5.0 & -2.0\end{array}$

Mass

Calc. Mass

$\mathrm{mDa} \quad \mathrm{PPM}$

DBE

i-FIT

Formula

472.3516

472.3553

$-3.7 \quad-7.8$

7.0

0.7

C3O H48

04

The HRESIMS Spectrum of Compound 1 


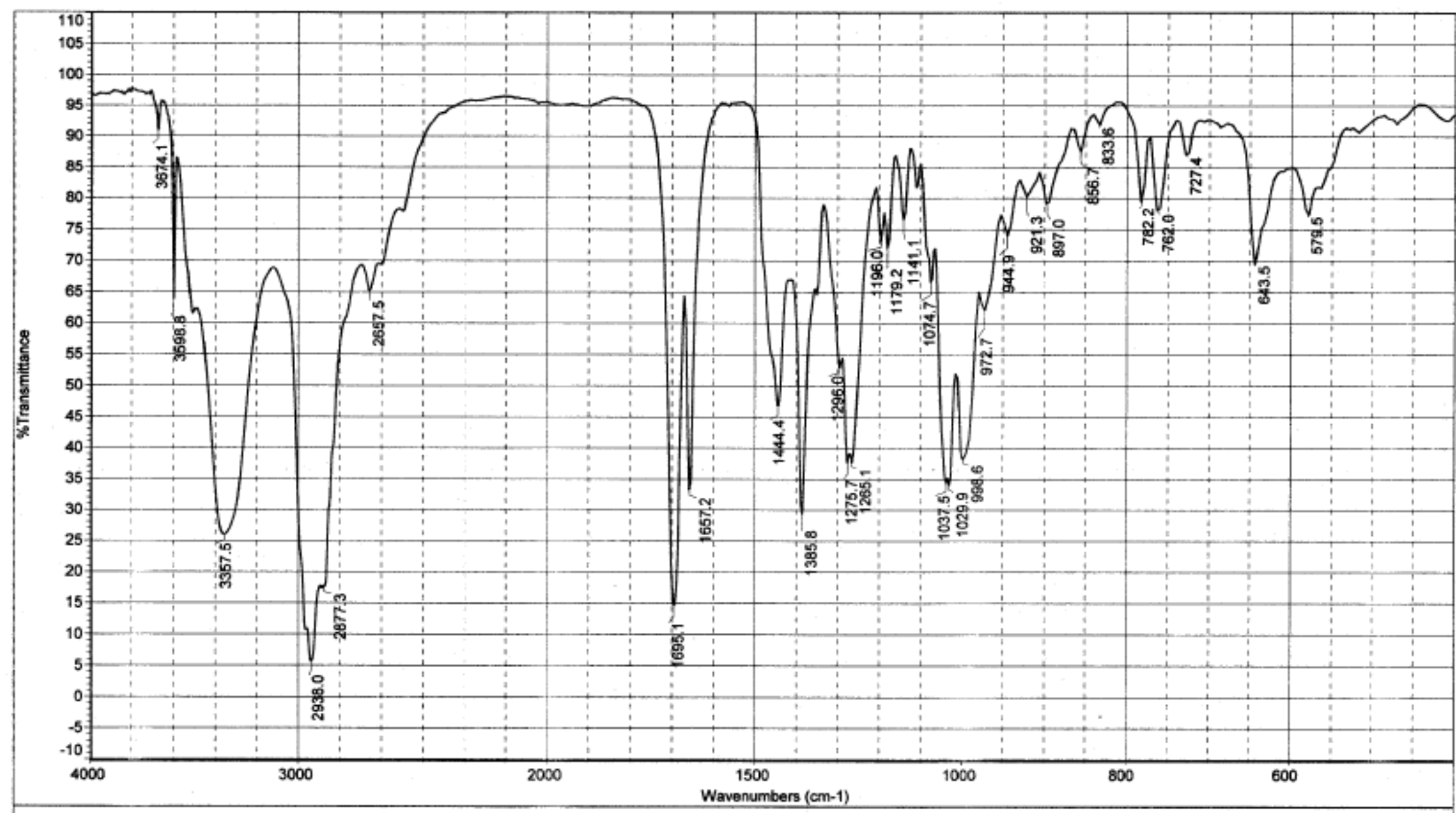

日期: 星期四 2月 27 16:46:44 2014 (GMT+08:0Sample Name: XJ - 59

(显微镜透射法 FT- IR Microscope Transmission)

扫描次数: 100

傅里叶变换显微镜红外(FT-IR Microscope)：Centaurus

分辫率: 8.000

美国热电公司(Thermo)傮里叶变换红外光谱仪:Nicolet 5700

The IR Spectrum of Compound 1 


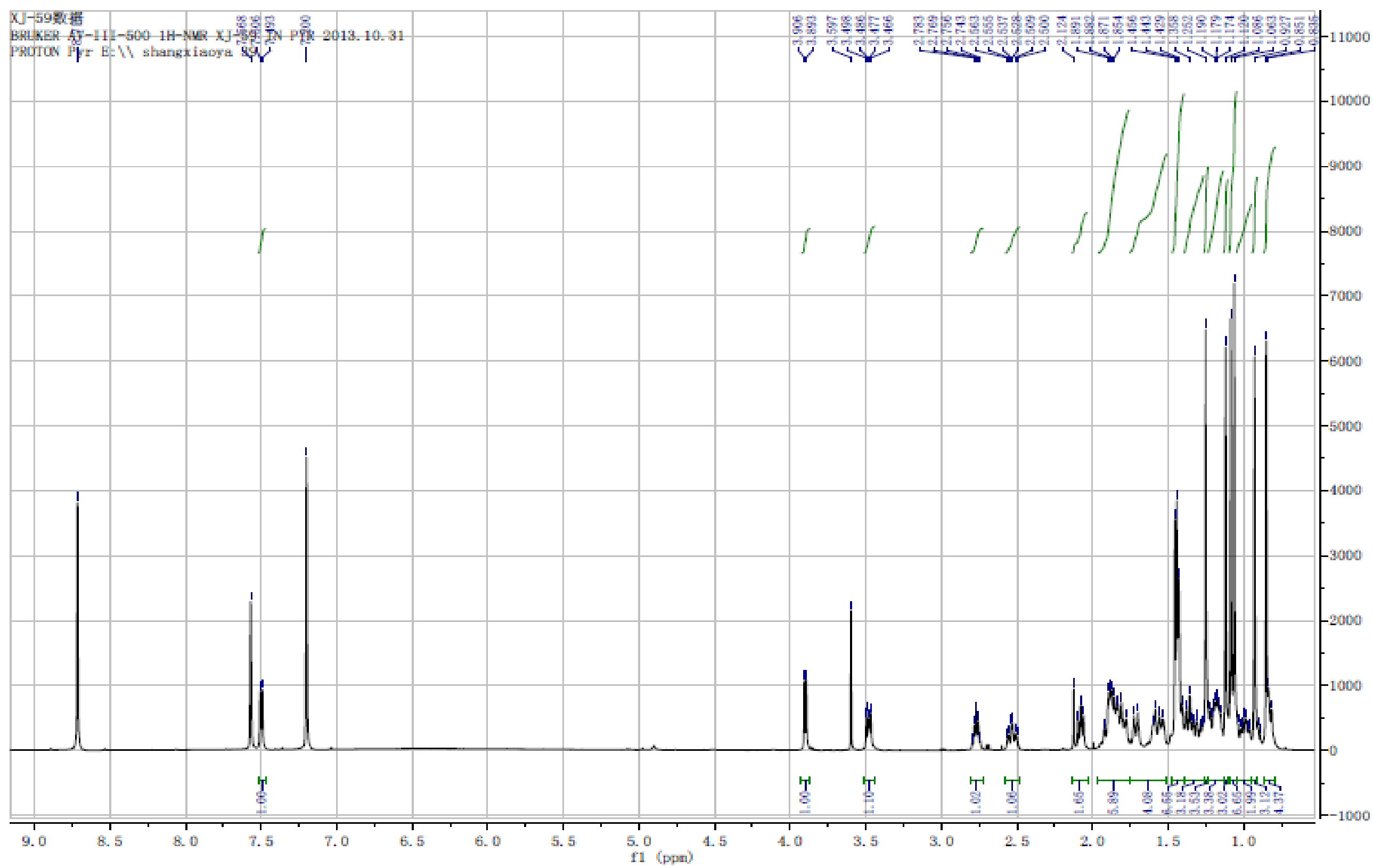

The ${ }^{1}$ H NMR Spectrum of Compound 1 


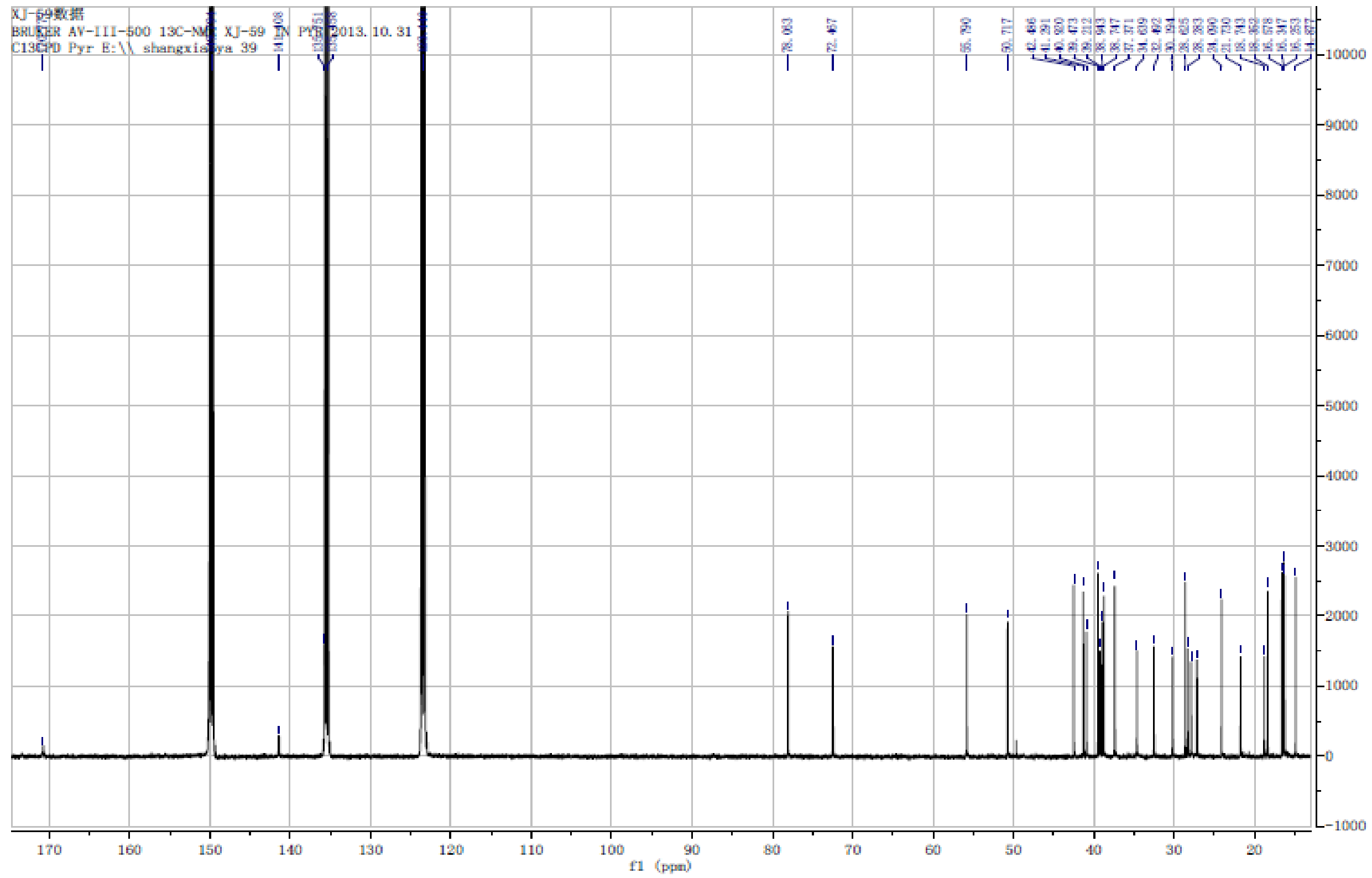

The ${ }^{13} \mathrm{C}$ NMR Spectrum of Compound 1 


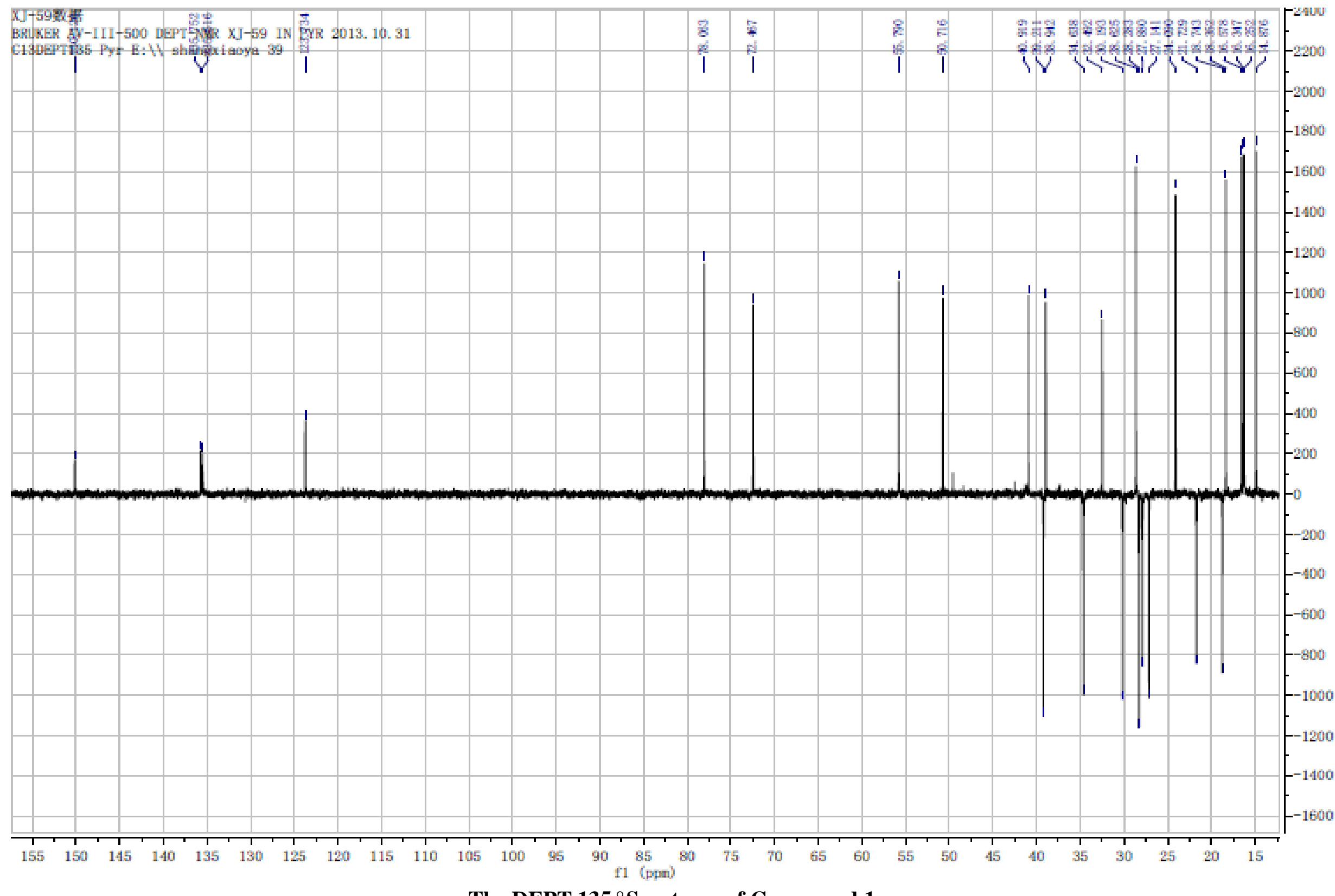

The DEPT-135 ${ }^{\circ}$ Spectrum of Compound 1 


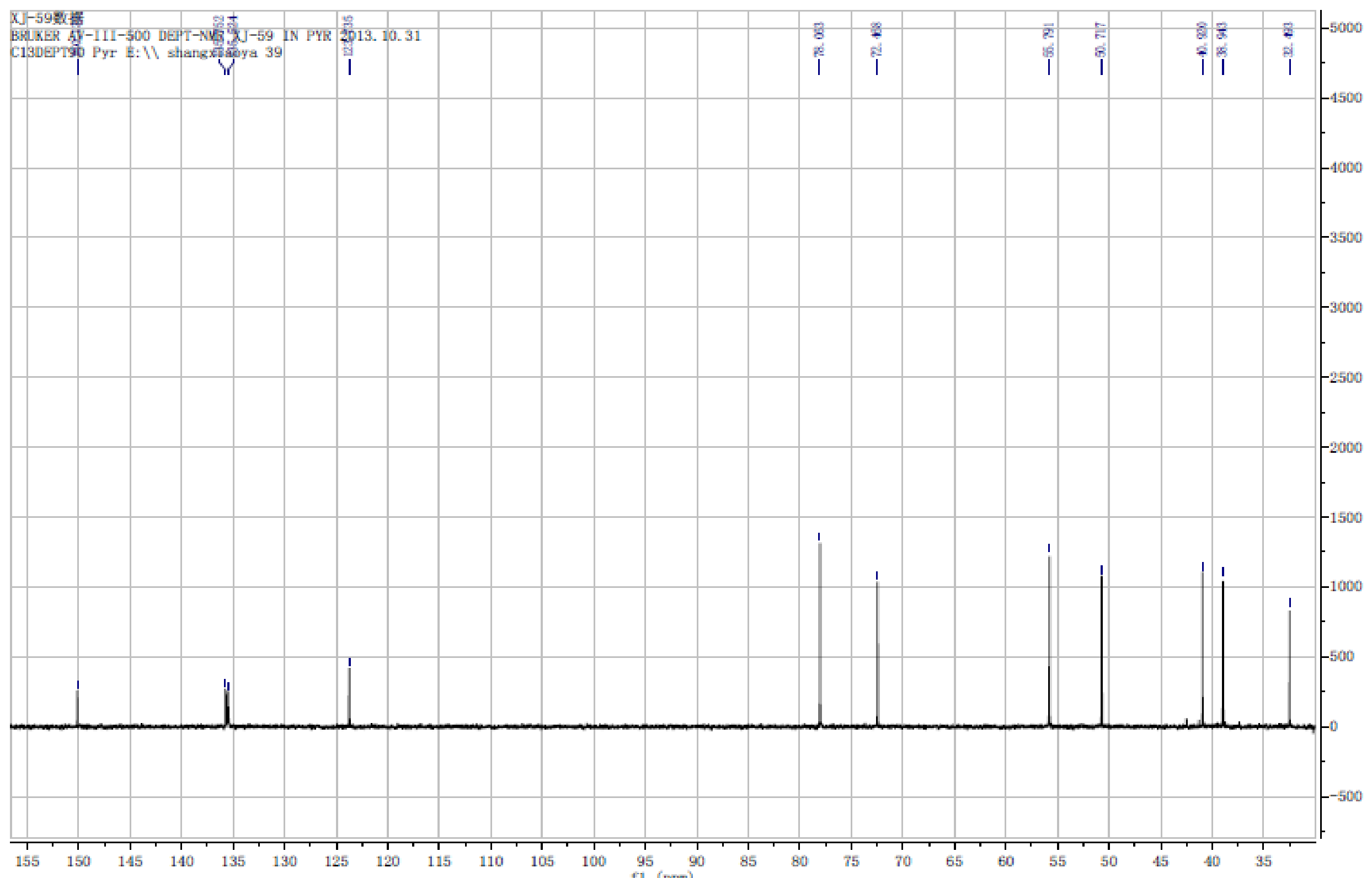

The DEPT-90 ${ }^{\circ}$ Spectrum of Compound 1 


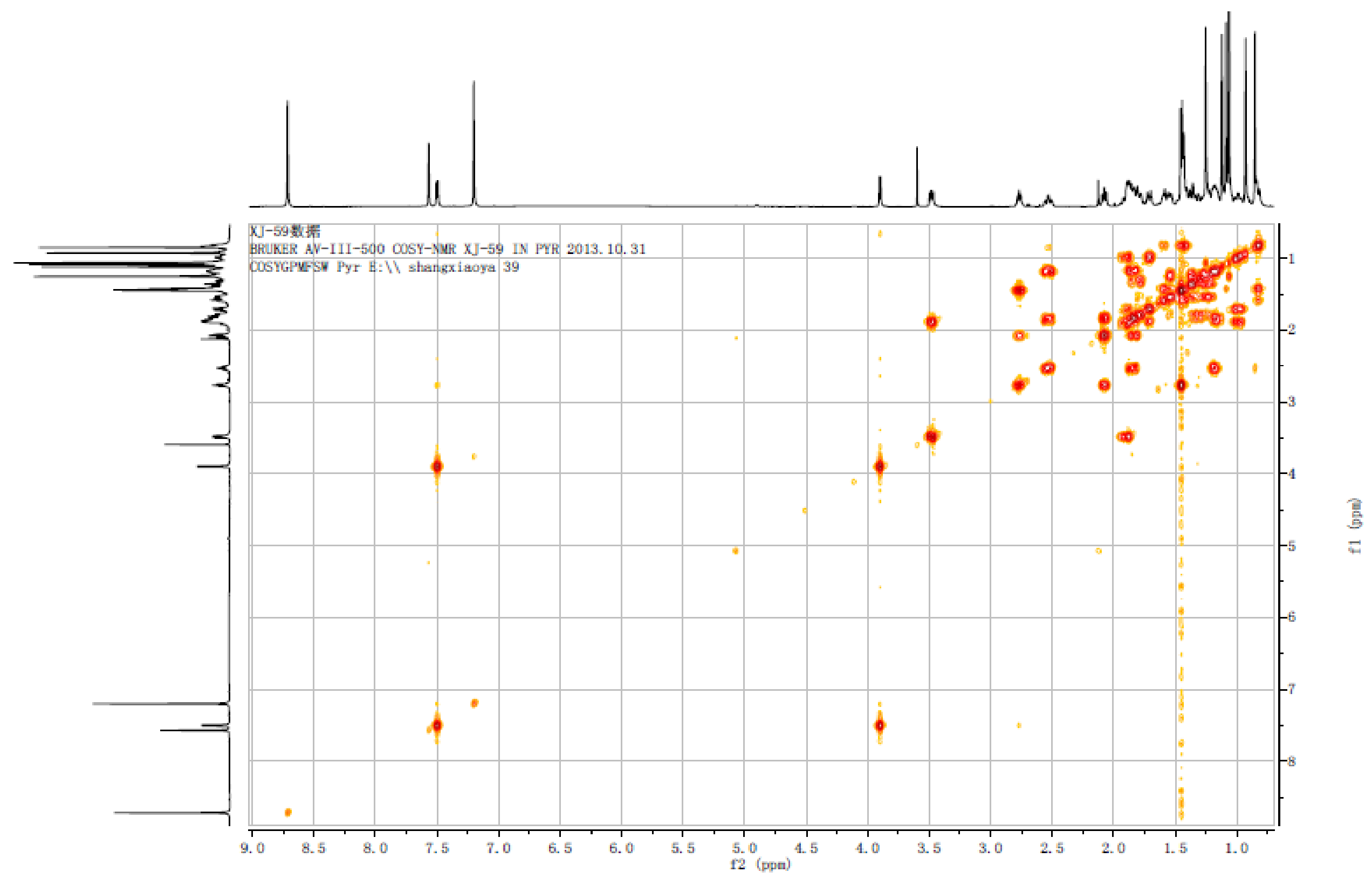

The ${ }^{1} \mathrm{H}-{ }^{1} \mathrm{H}$ COSY Spectrum of Compound 1 


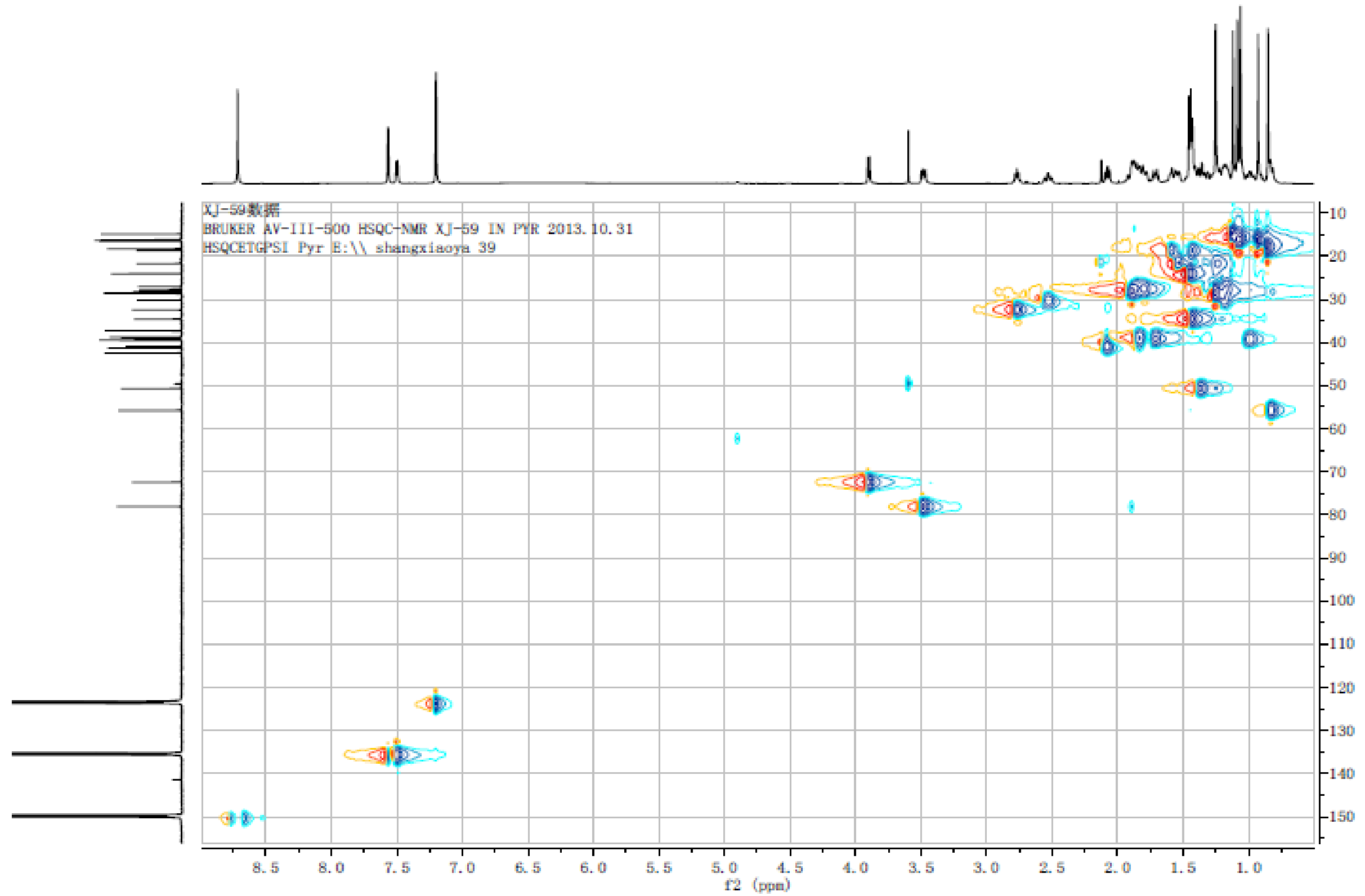

The HSQC Spectrum of Compound 1

S11 


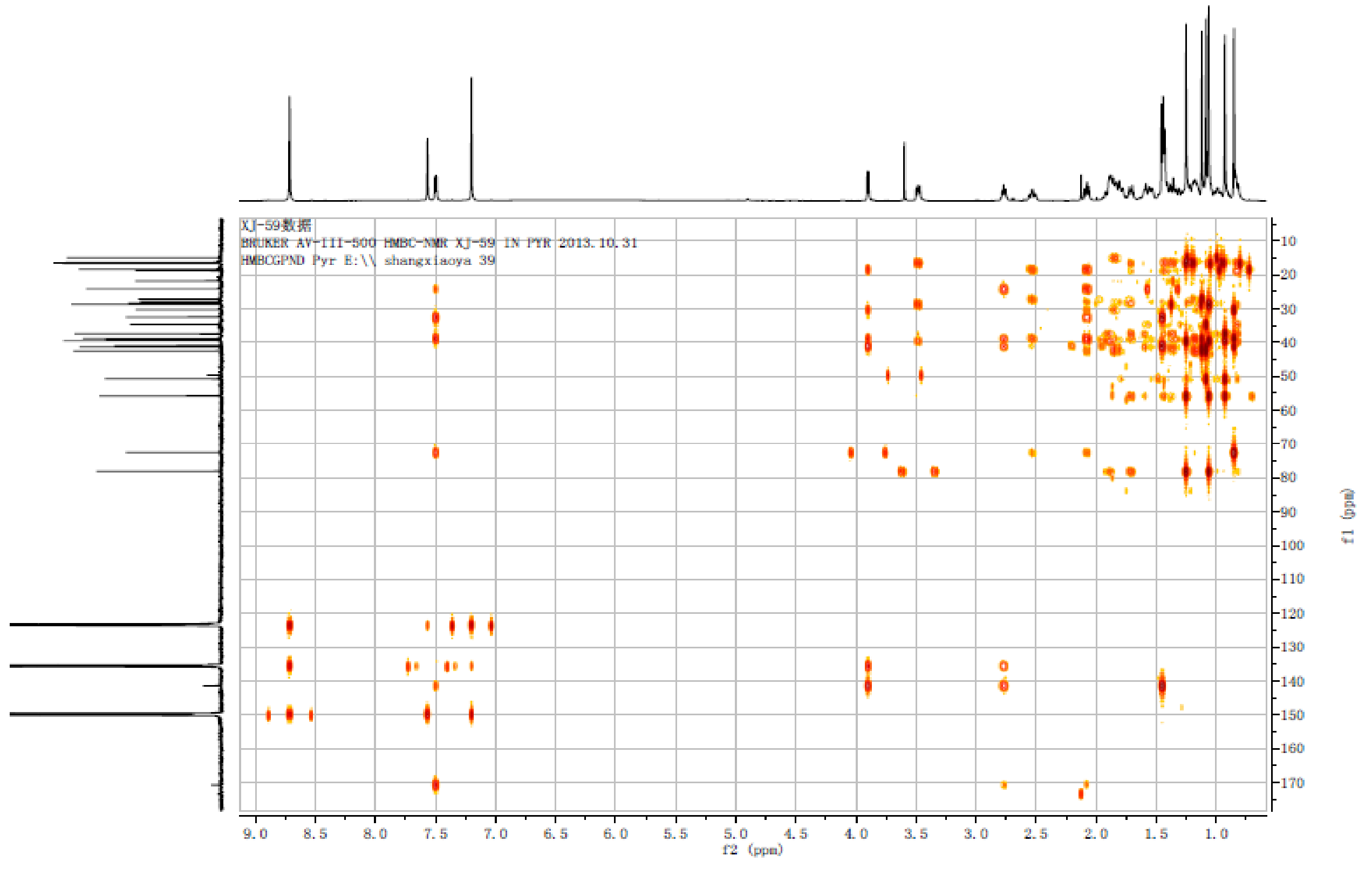

The HMBC Spectrum of ompound 1 


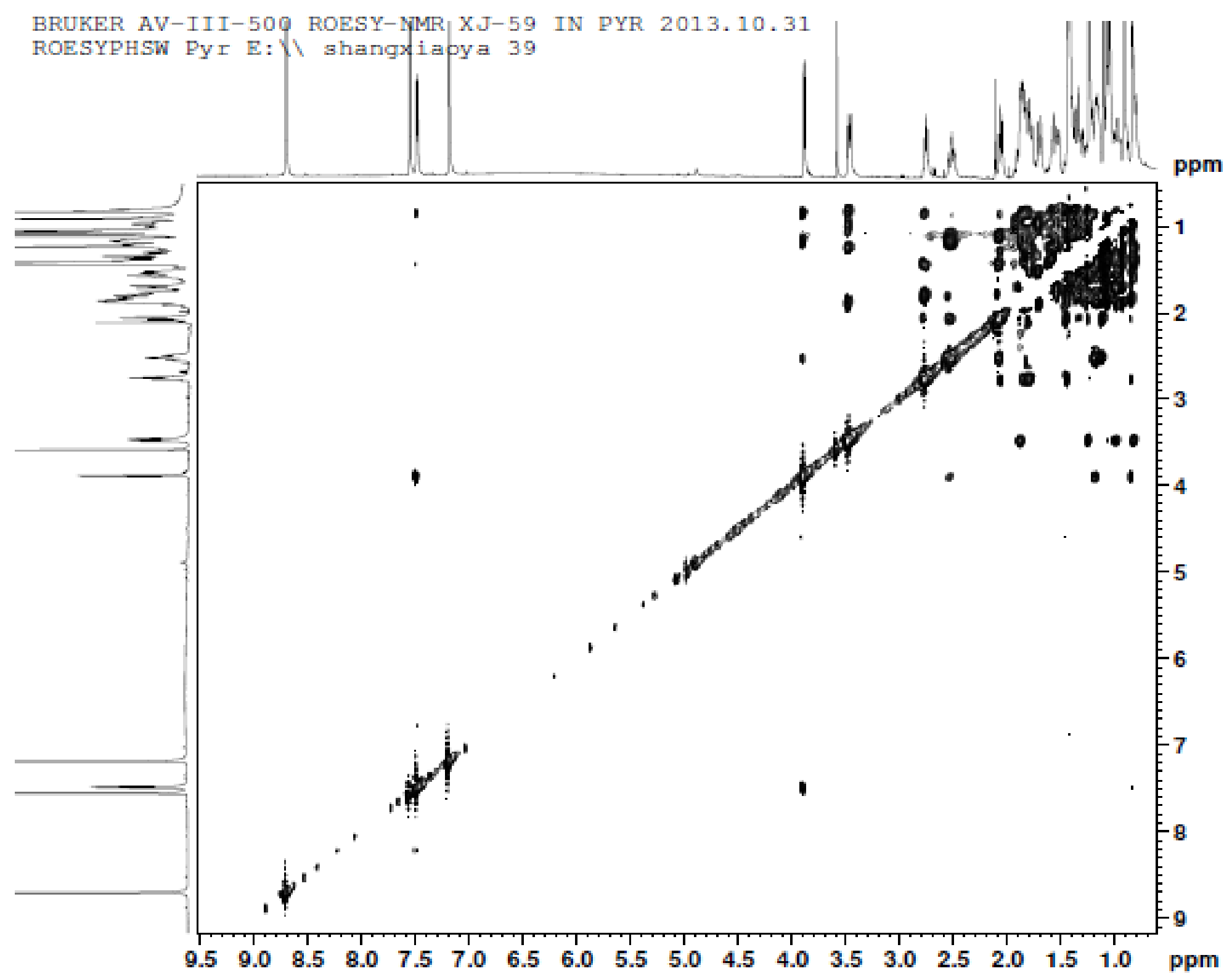

errefer

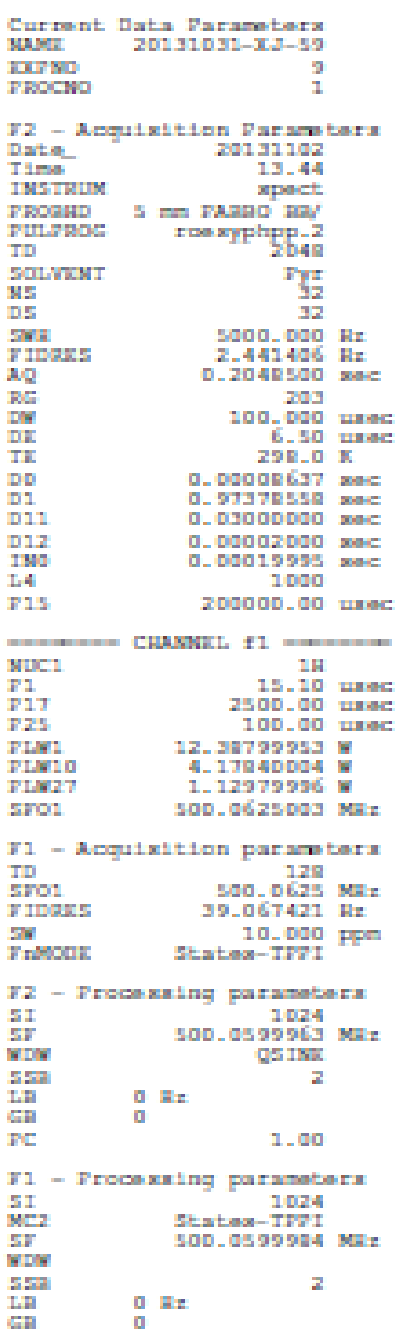

The ROESY Spectrum of Compound 1 
Single Mass Analysis (displaying only valid results)

Tolerance $=10.0$ PPM / DBE: $\min =-2.0, \max =40.0$

Selected filters: None

Monoisotopic Mass, Odd and Even Electron lons

30 formula(e) evaluated with 1 results within limits (up to 50 best isotopic matches for each mass)

Elements Used:

$\begin{array}{lll}C: 0-500 & H: 0-1000 & 0: 0-4\end{array}$

EI

XJ-64-HREI 20 (1.067) Cn (Cen,5, 30.00, Ht); Sm (Mn, 2×3.00); Cm (20)

14-May-2014

100- 470.3359
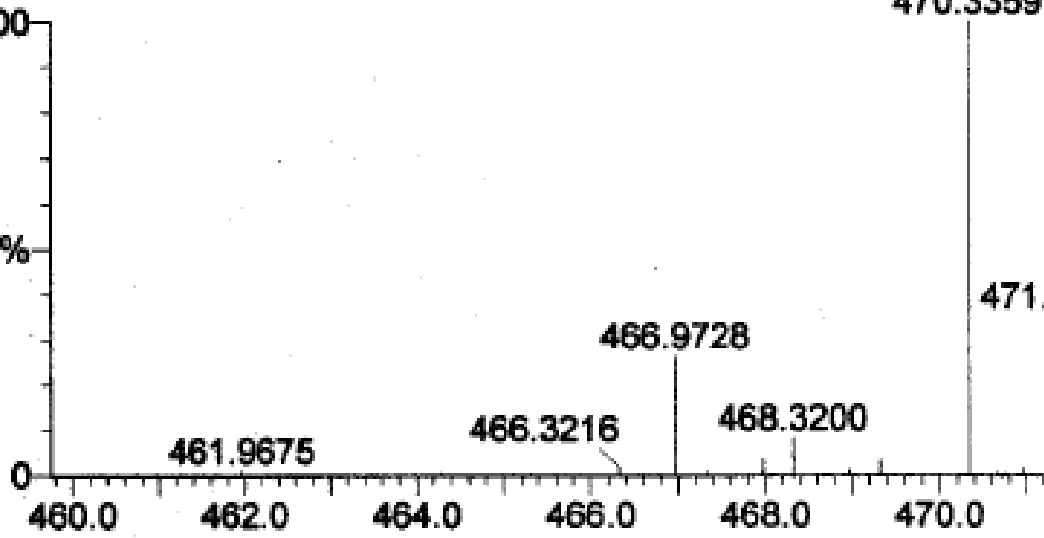

$2.95 \mathrm{e} 3$

Minimum:

Maximum:

$\begin{array}{lll}5.0 & 10.0 & -2.0 \\ & 40.0\end{array}$

Mass

Calc. Mass

$\mathrm{mDa}$

PPM

DBE

i-FIT

Formula

470.3359

470.3396

$-3.7$

$-7.9$

8.0

1.6

C30 H46 O4

The HRESIMS Spectrum of Compound 2 


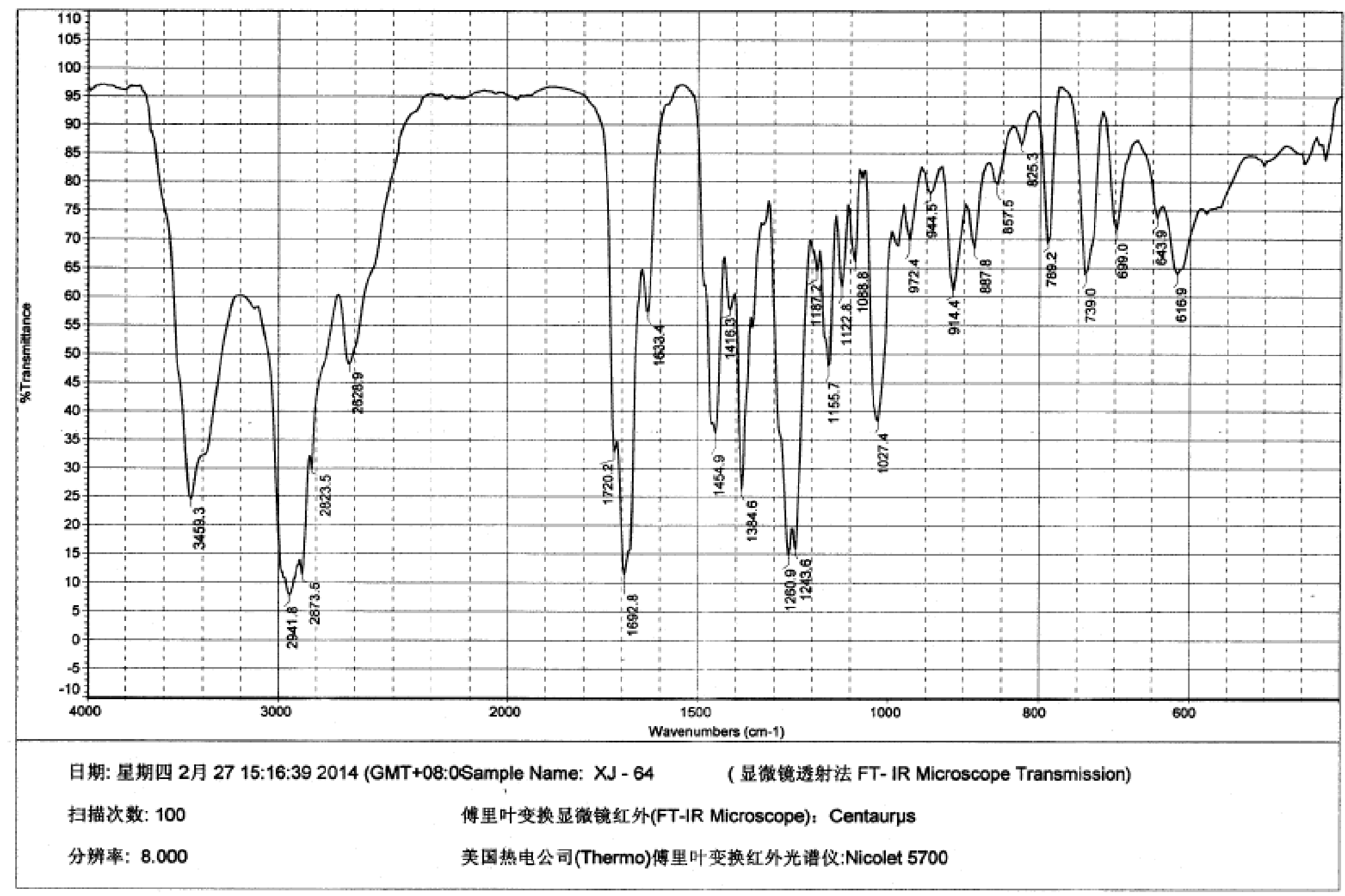

The IR Spectrum of Compound 2

S15 


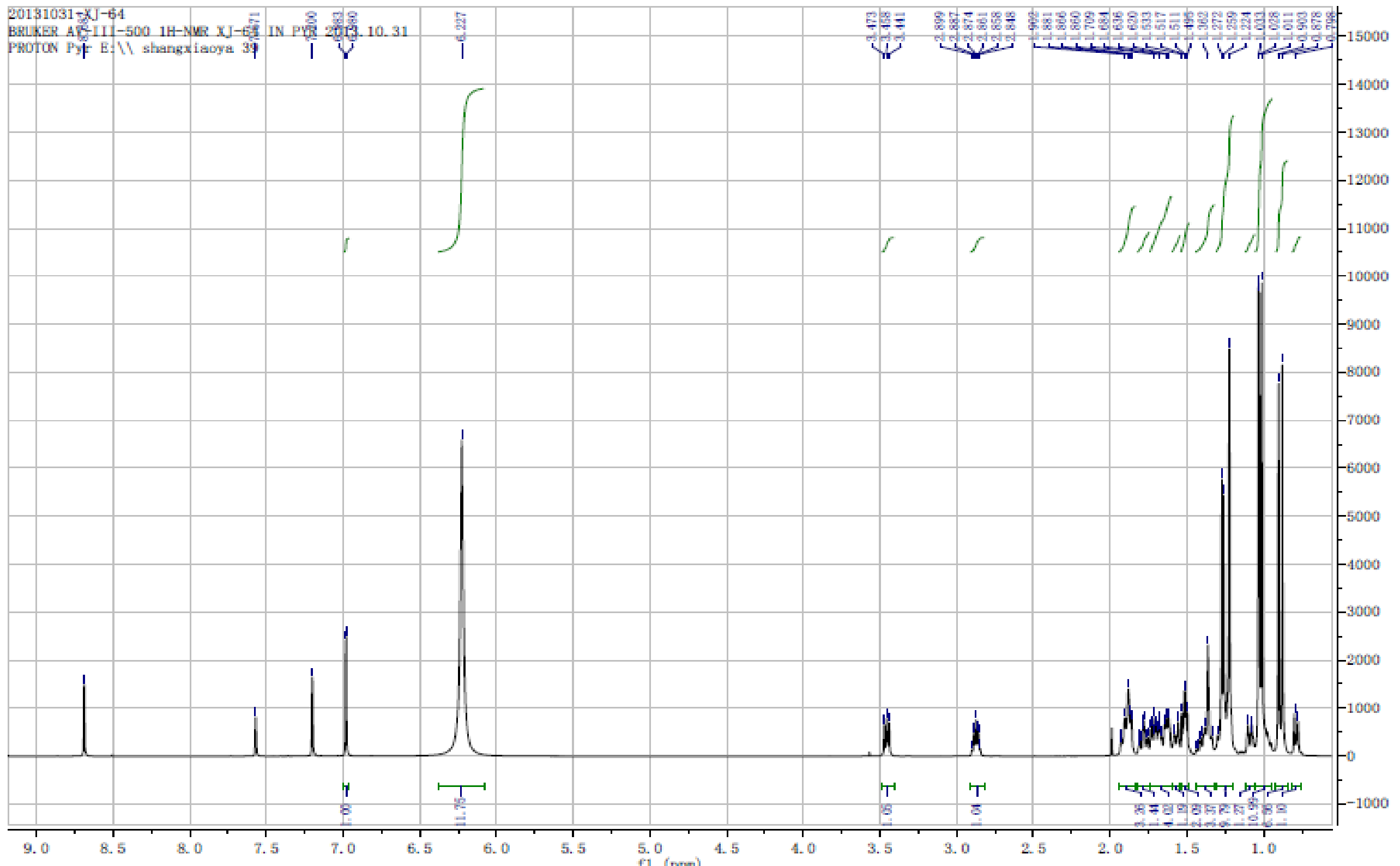

The ${ }^{1}$ H NMR Spectrum of Compound 2 


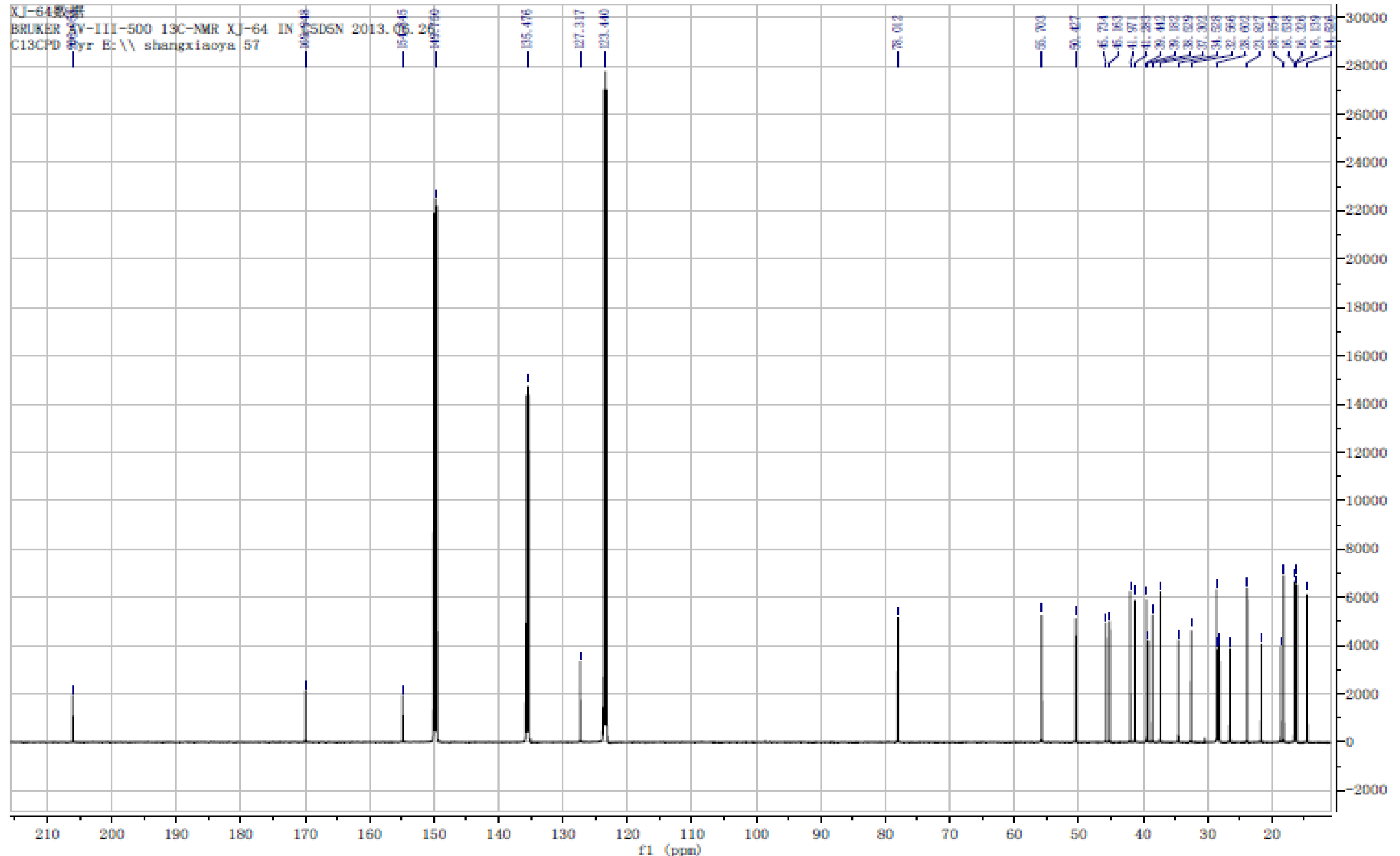

The ${ }^{13} \mathrm{C}$ NMR Spectrum of Compound 2 


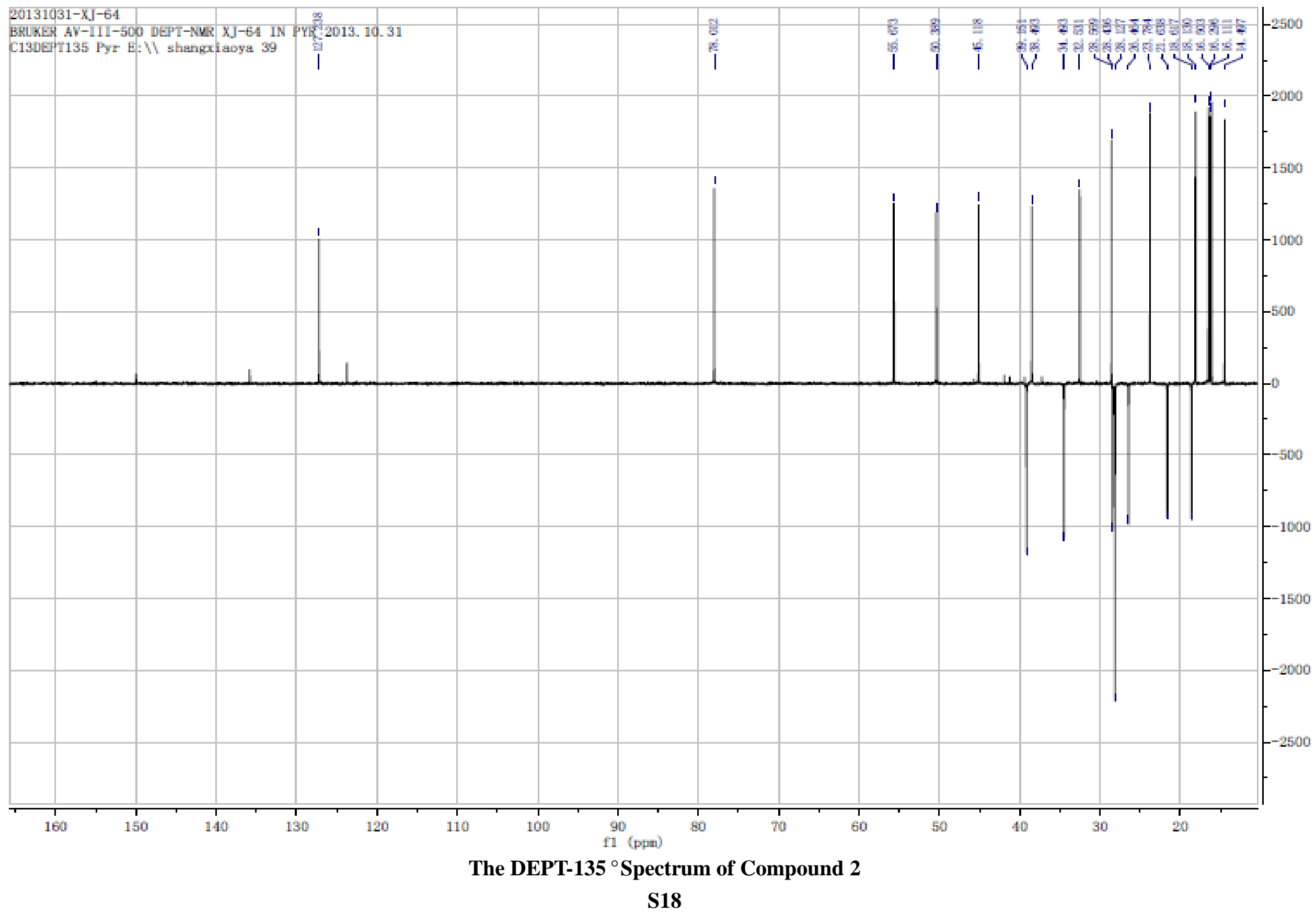




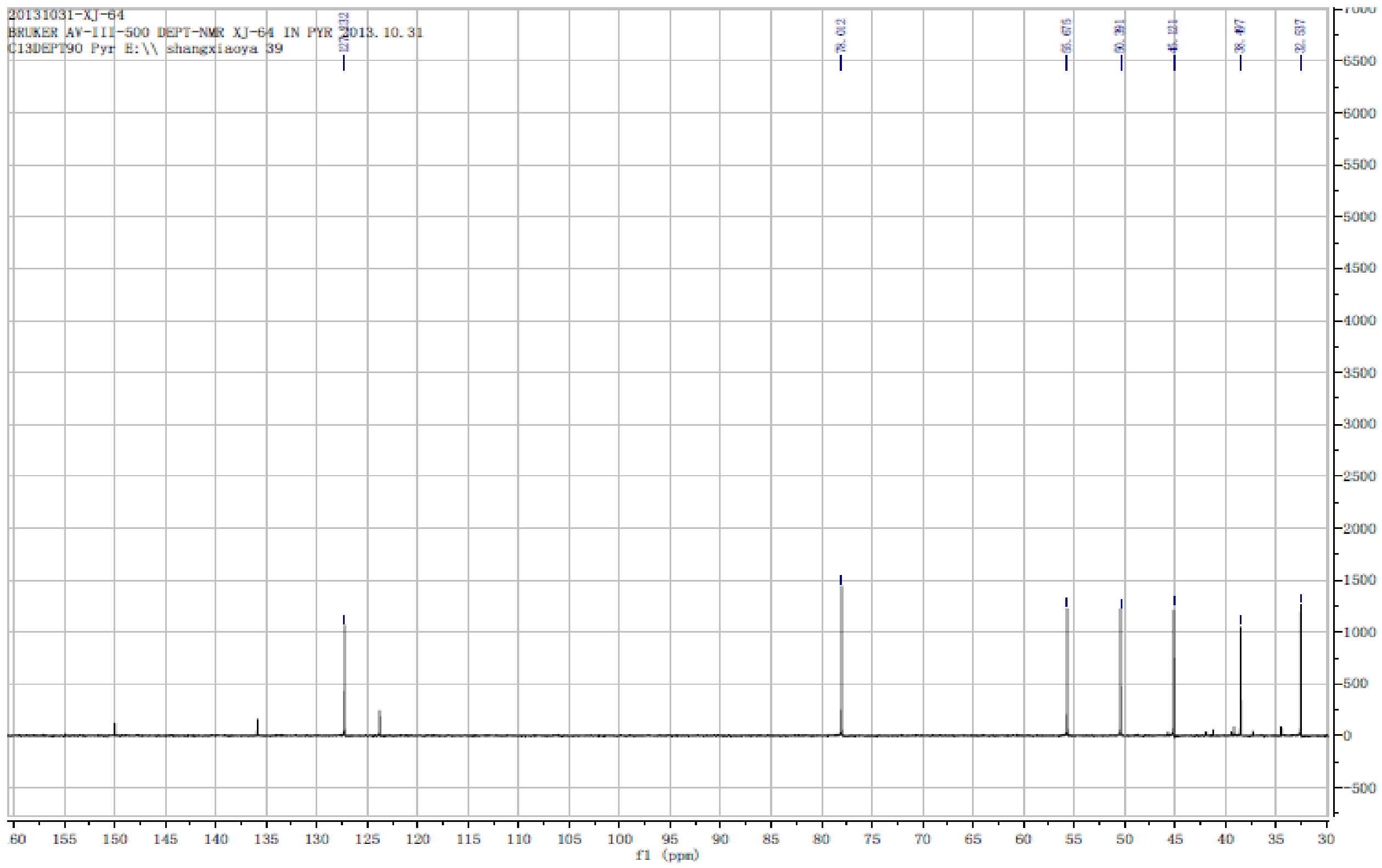

The DEPT-90 ${ }^{\circ}$ Spectrum of Compound 2

S19 


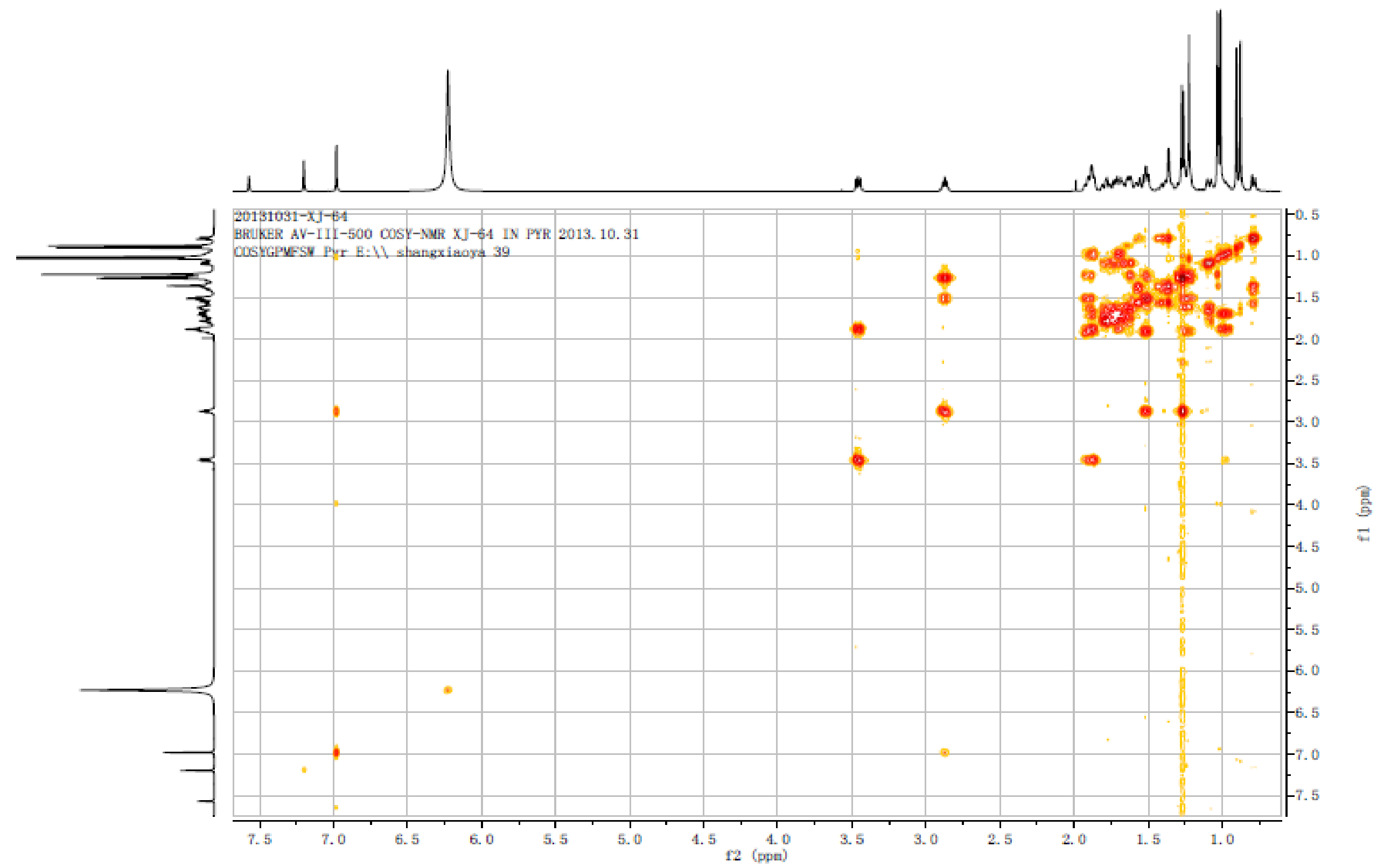

The ${ }^{1} \mathrm{H}-{ }^{1} \mathrm{H}$ COSY Spectrum of Compound 2 


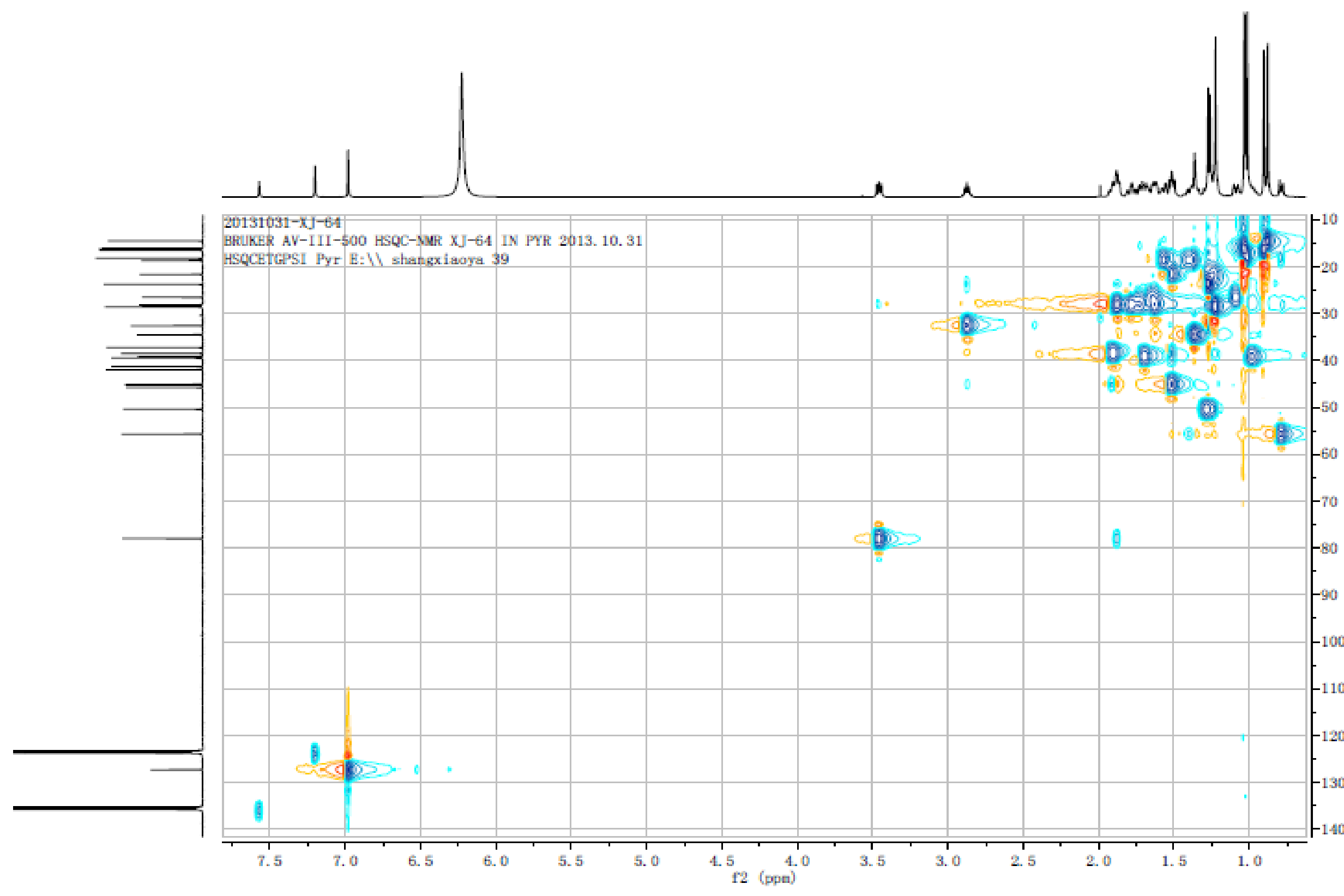

The HSQC Spectrum of Compound 2

S21 


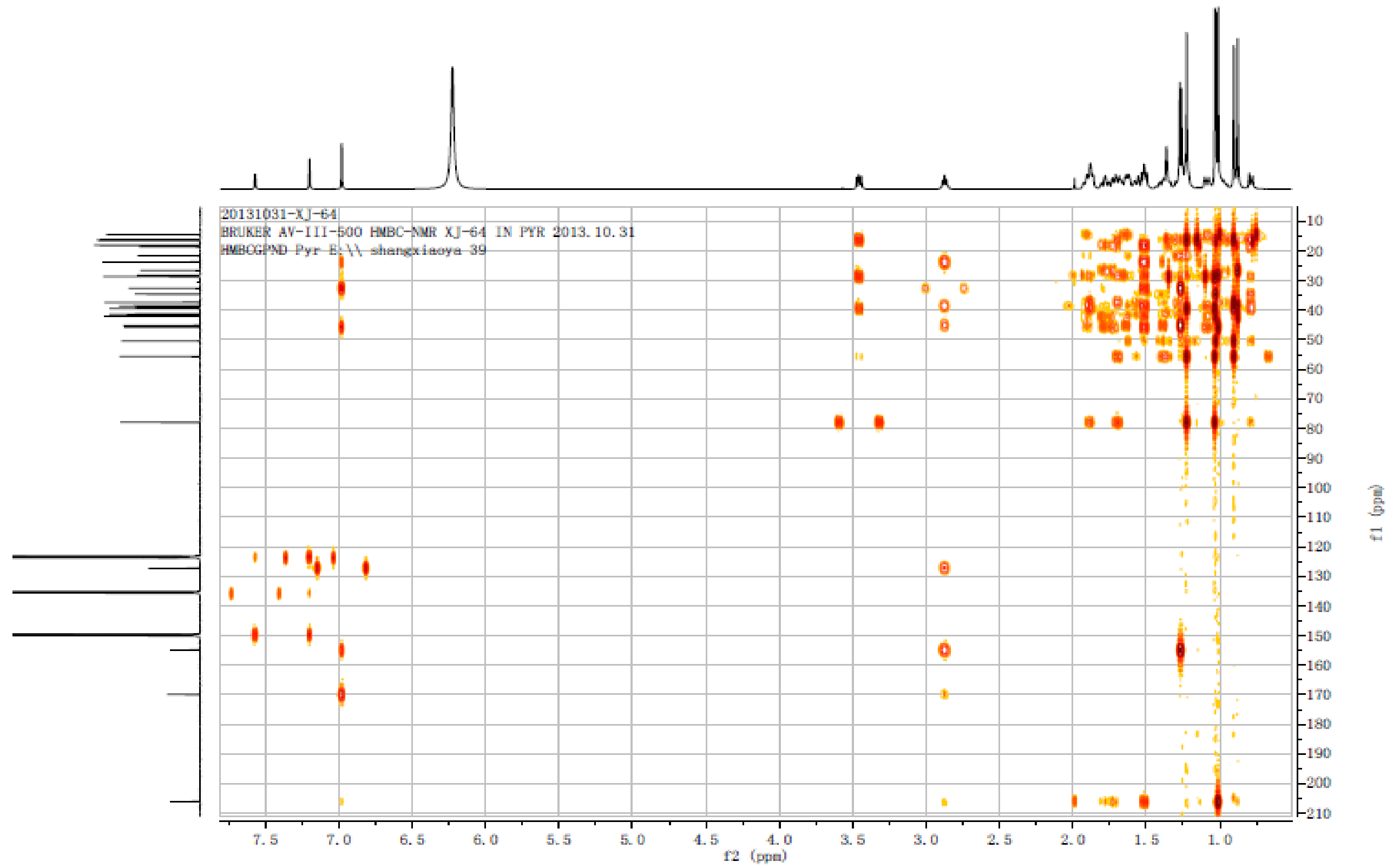

The HMBC Spectrum of ompound 2 
BRUKER AV-III-500 ROESY-NMR XJ-64 IN PYR 2013.10.31

ROESYPHSW PYI E: \ shangxiaoya 39

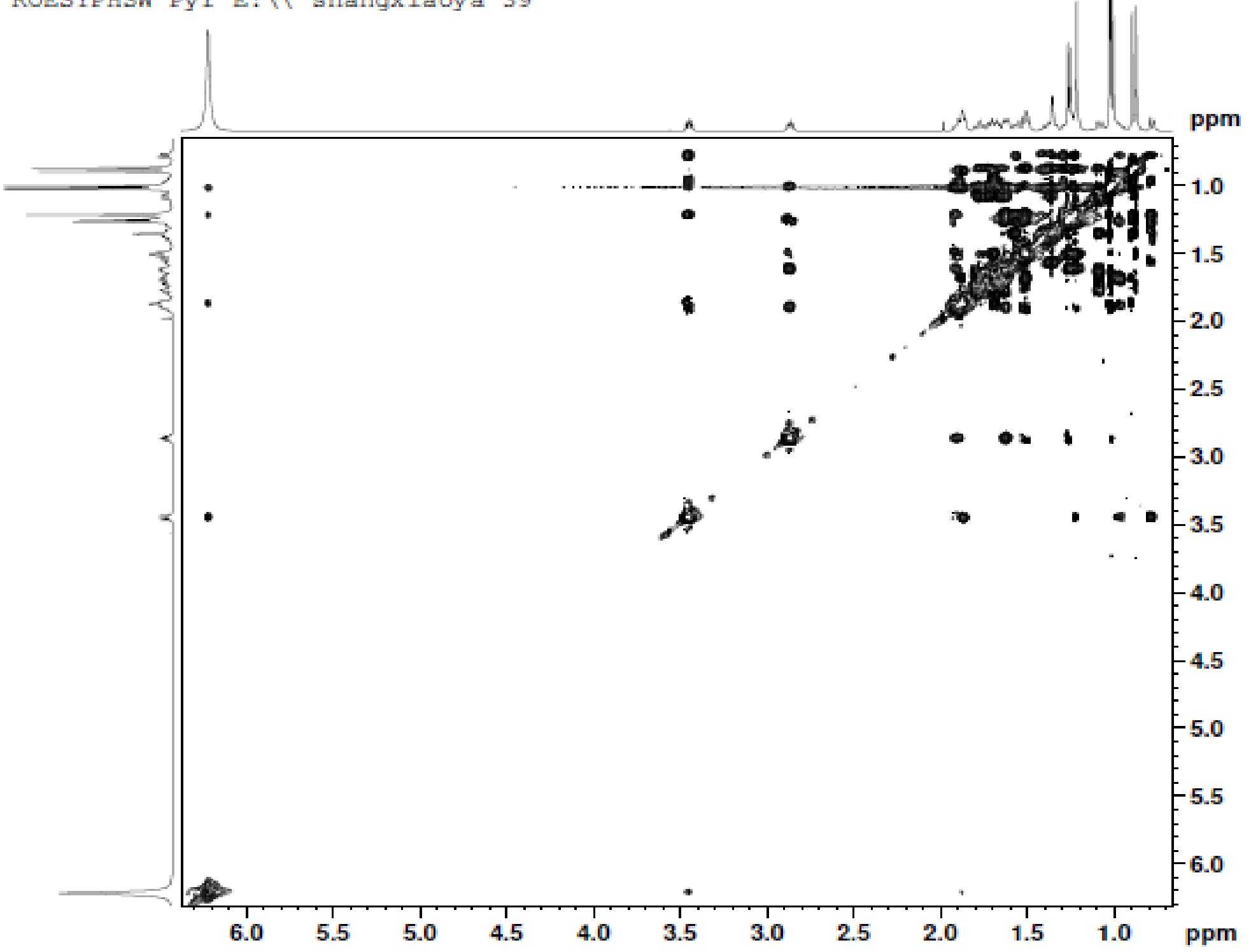

ar

Curront Data parametark

Thock

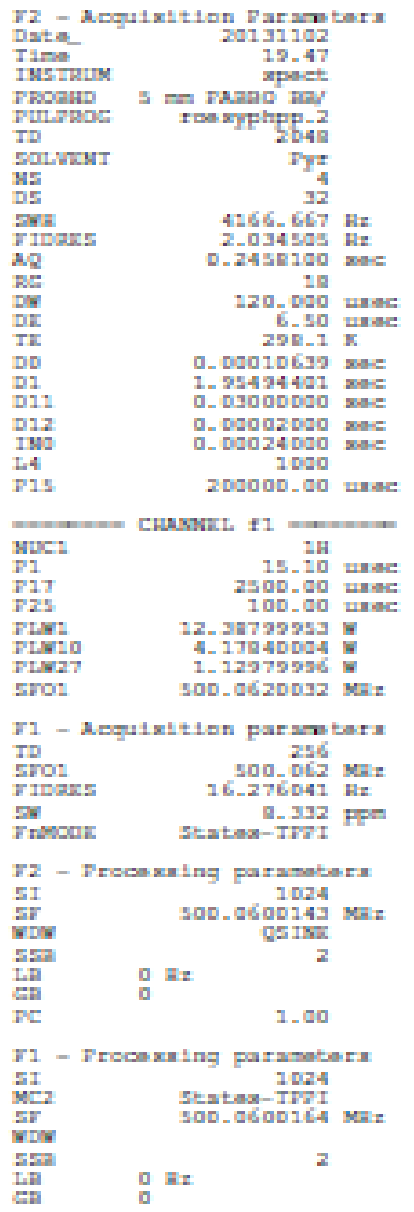

The ROESY Spectrum of Compound 2 

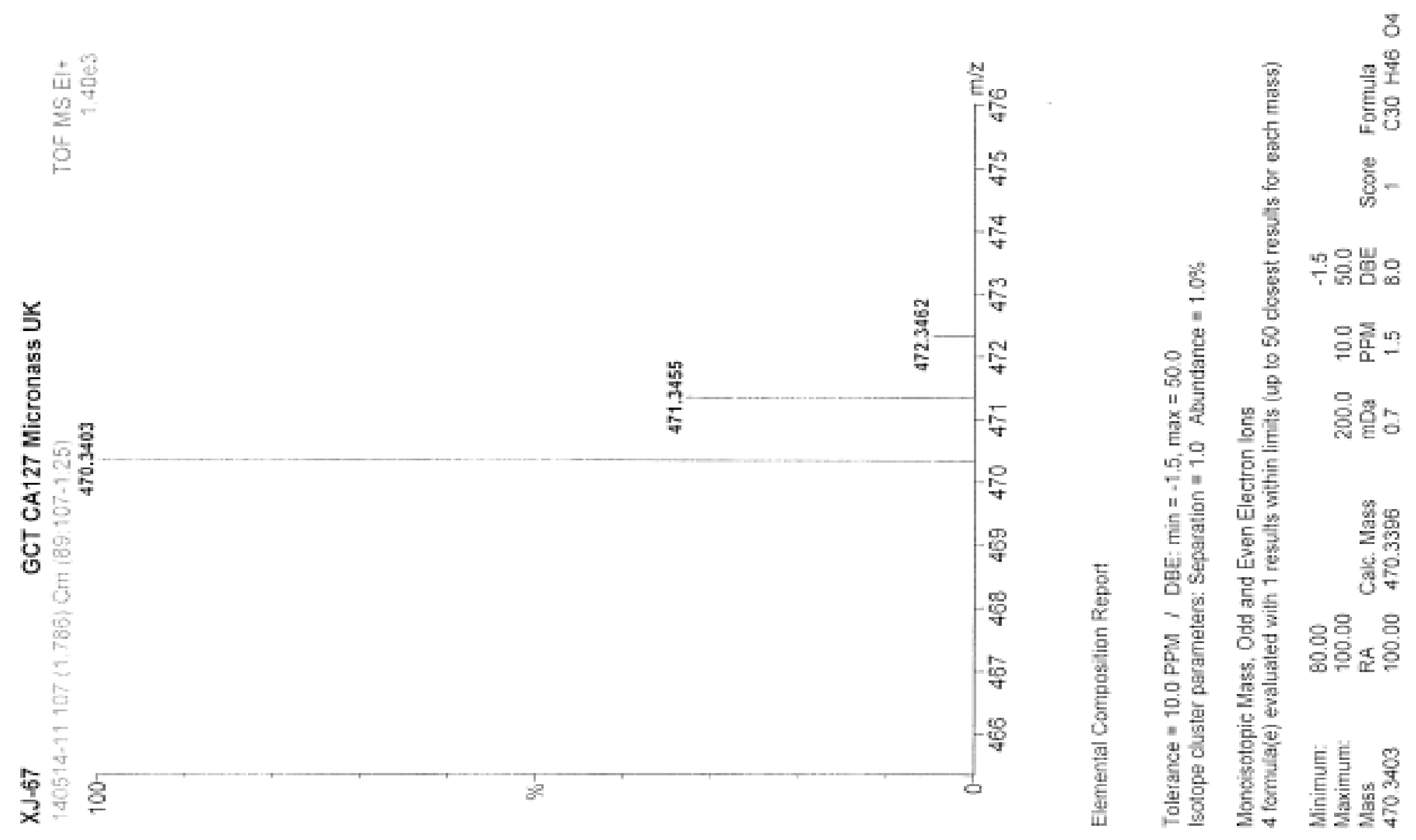

The HRESIMS Spectrum of Compound 3

S24 


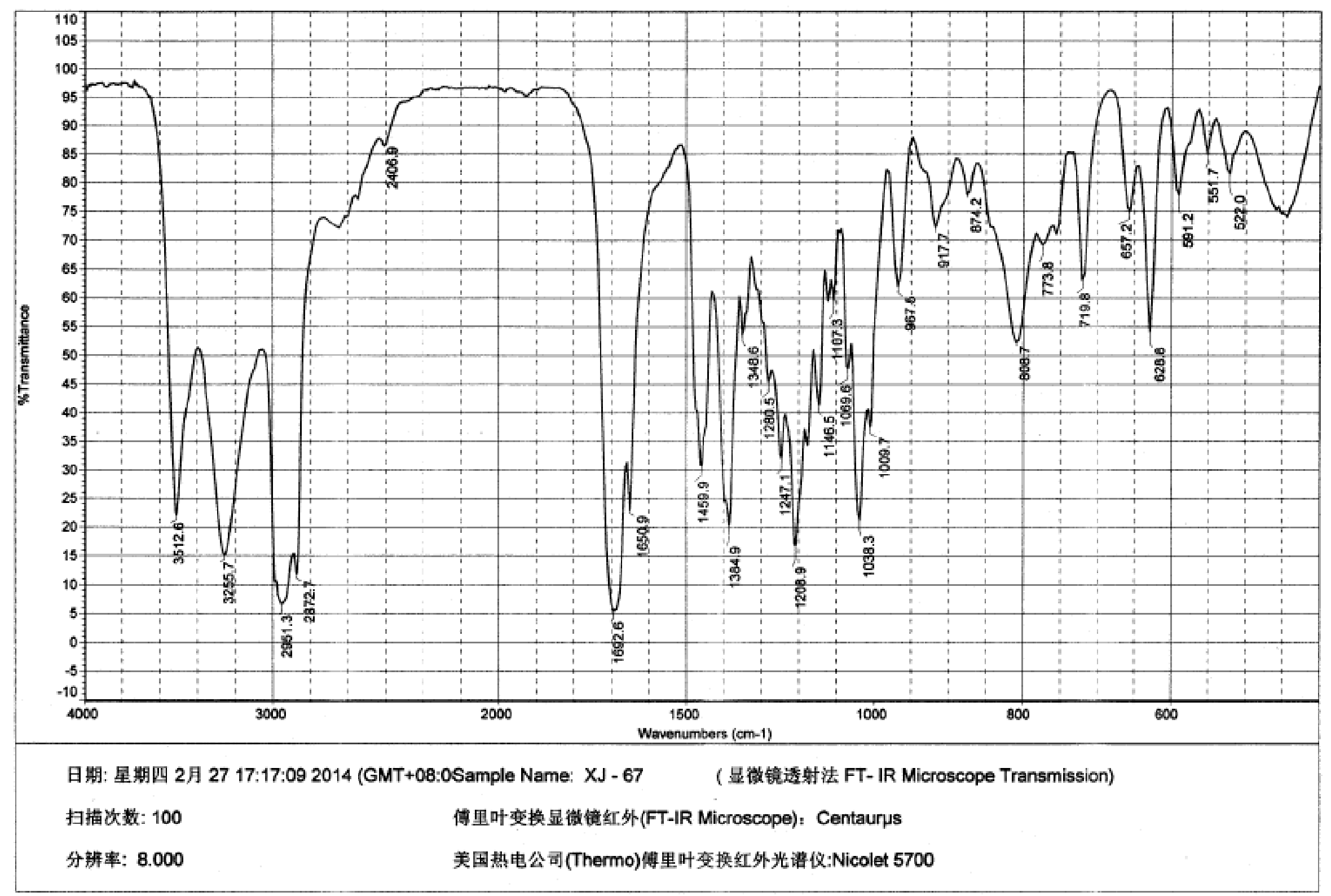

The IR Spectrum of Compound 3 


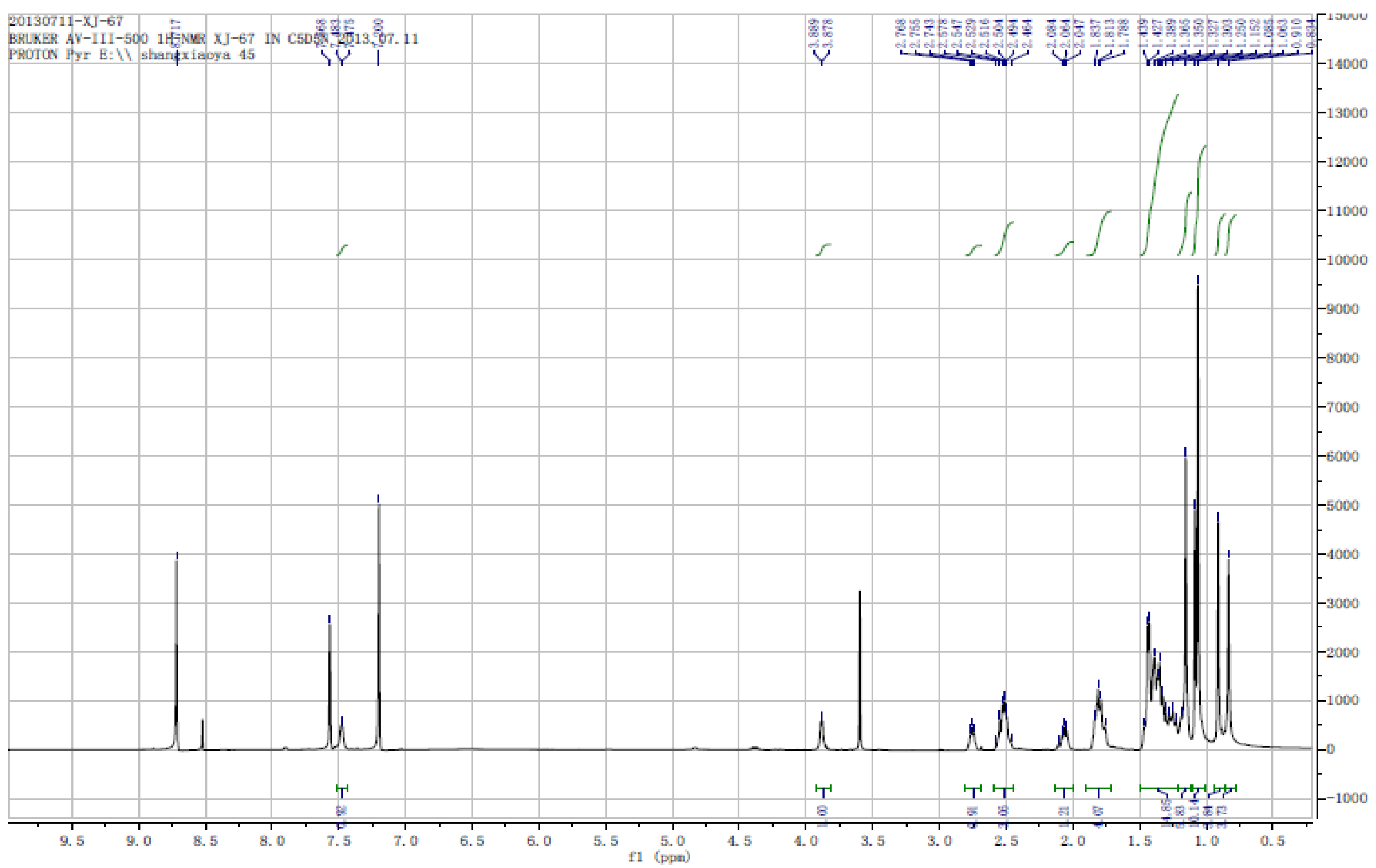

The ${ }^{1}$ H NMR Spectrum of Compound 3 


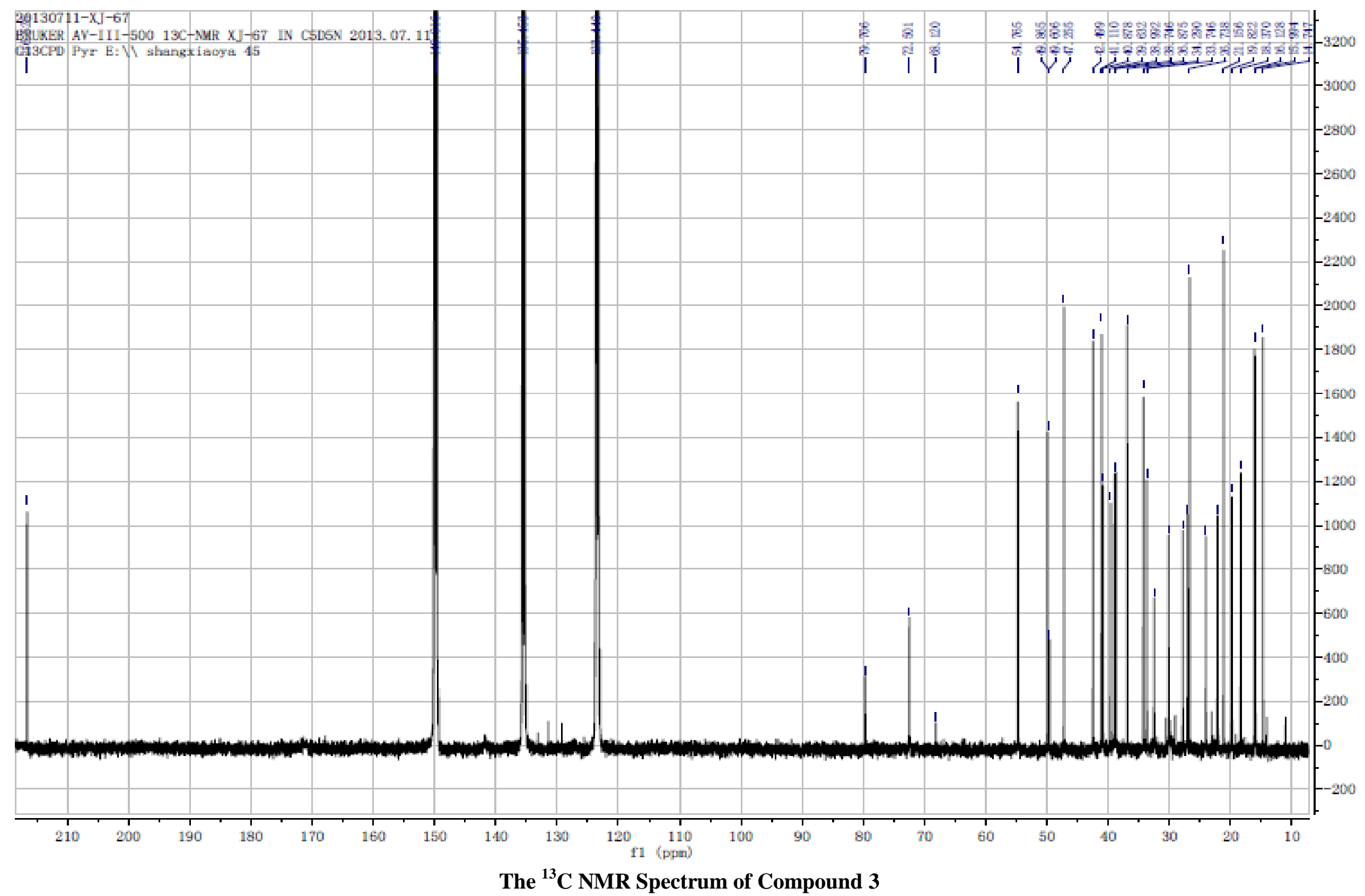

The ${ }^{13} \mathrm{C}$ NMR Spectrum of Compound 3 


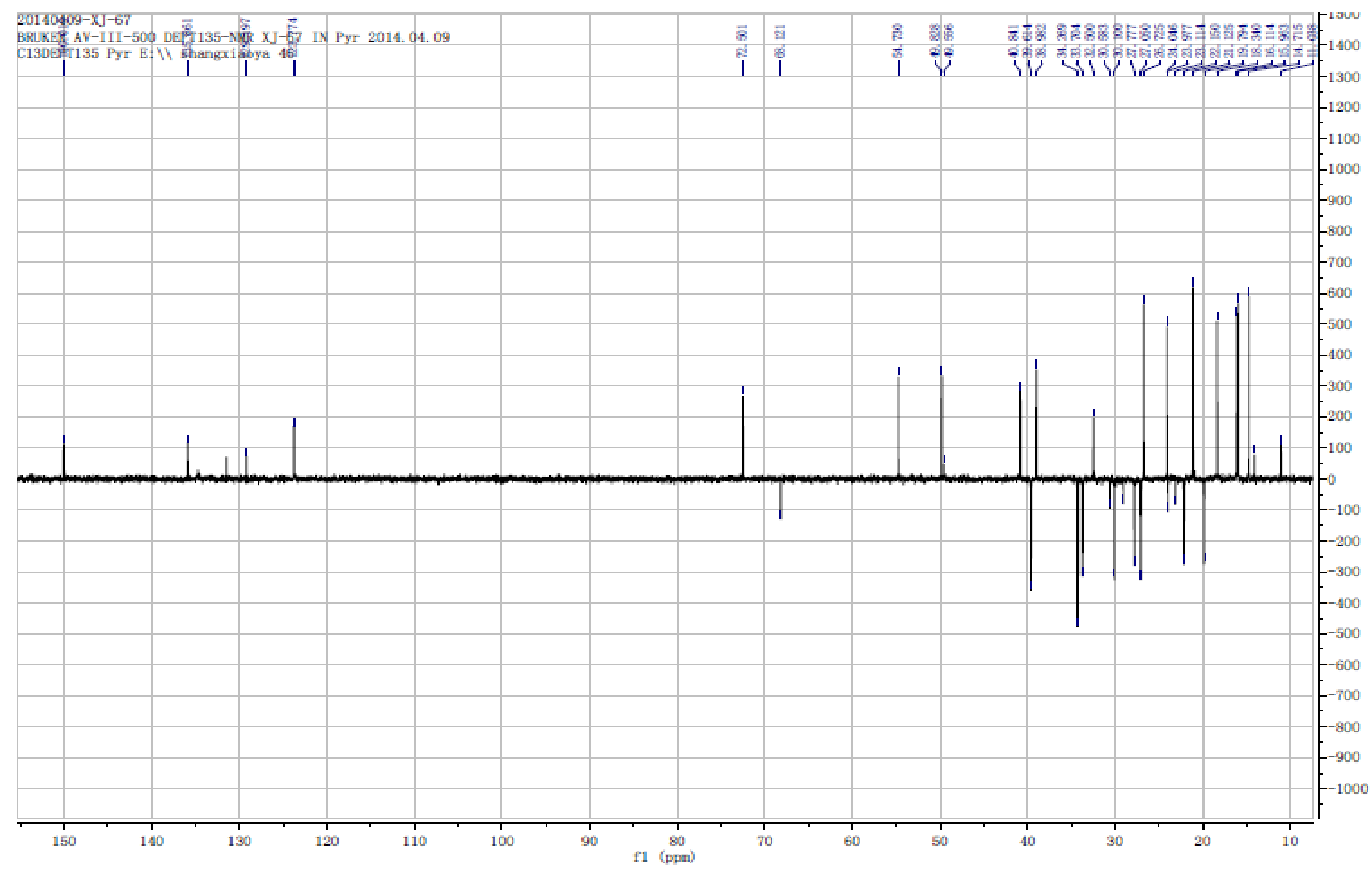

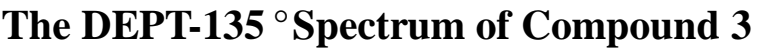




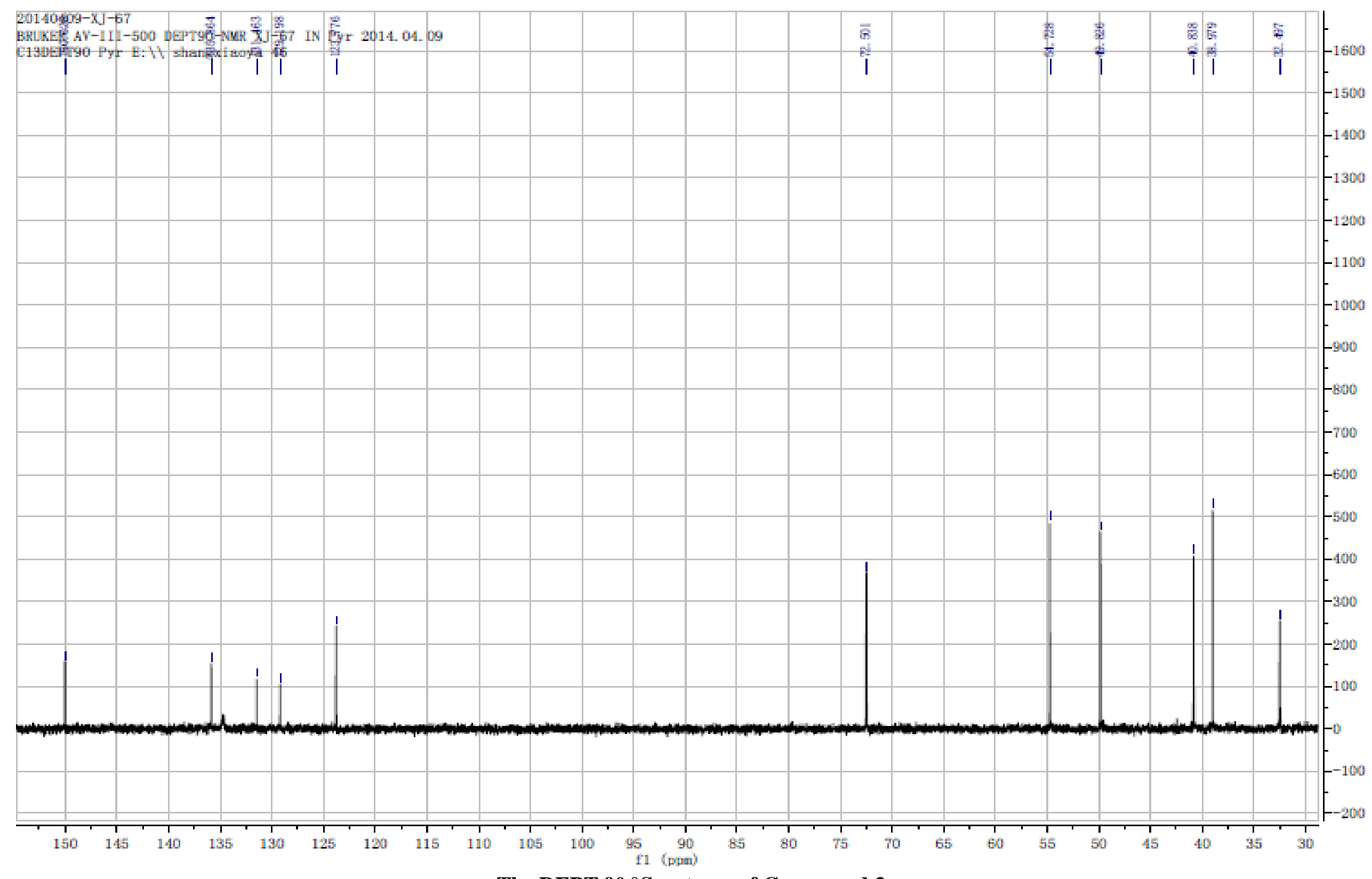

The DEPT-90 ${ }^{\circ}$ Spectrum of Compound 3

S29 


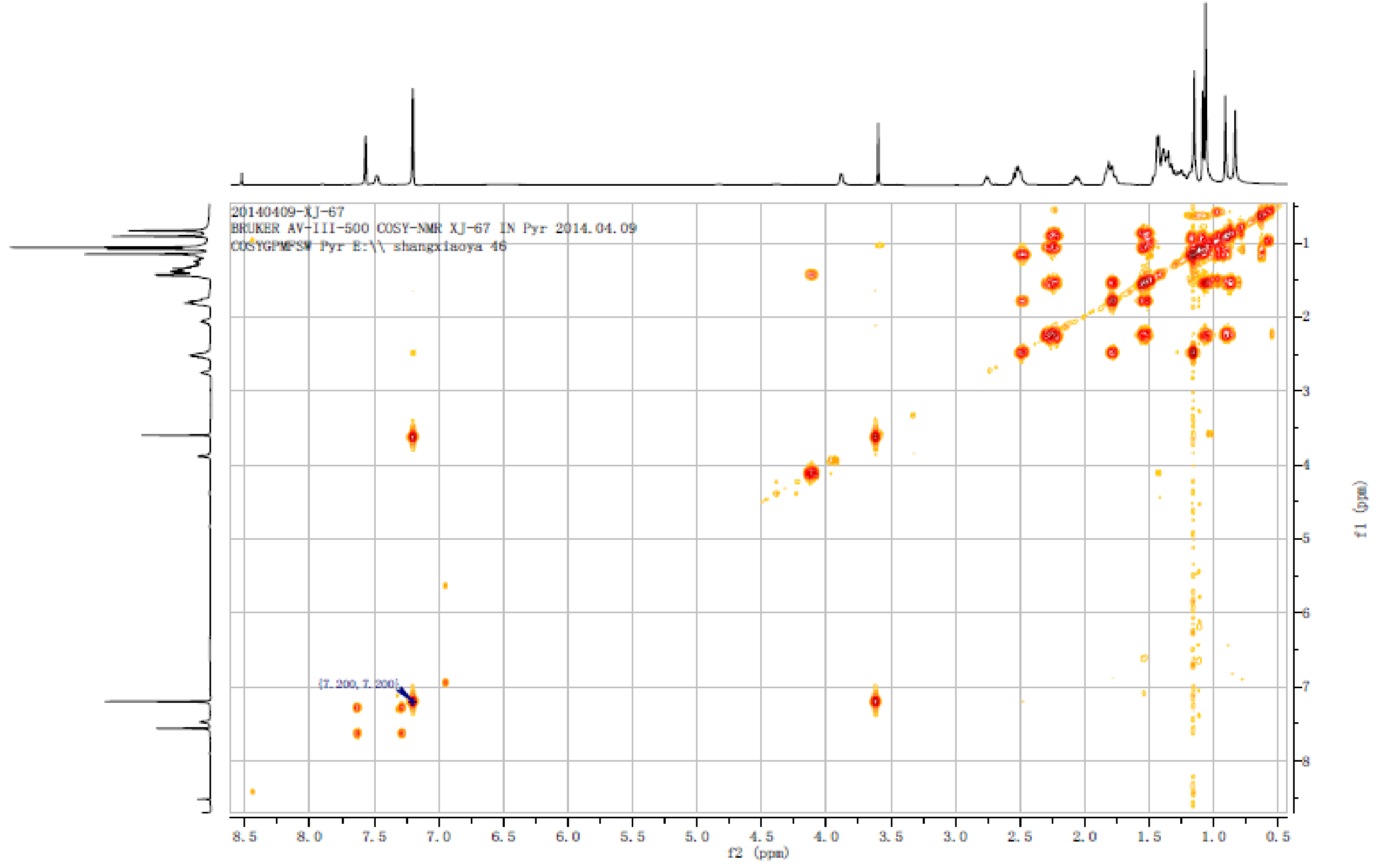

The ${ }^{1} \mathrm{H}-{ }^{1} \mathrm{H}$ COSY Spectrum of Compound 3

$$
\text { S30 }
$$




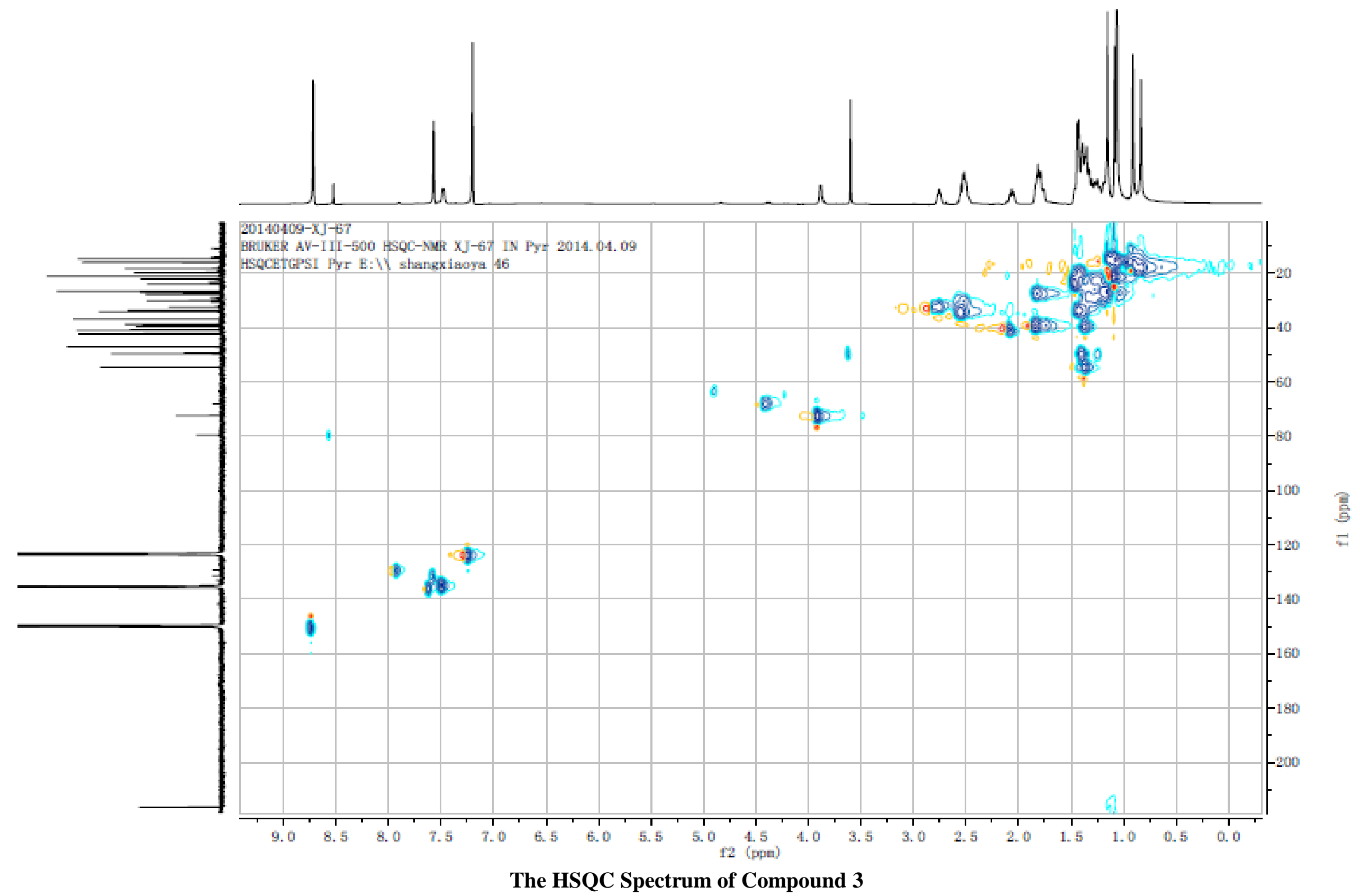

S31 


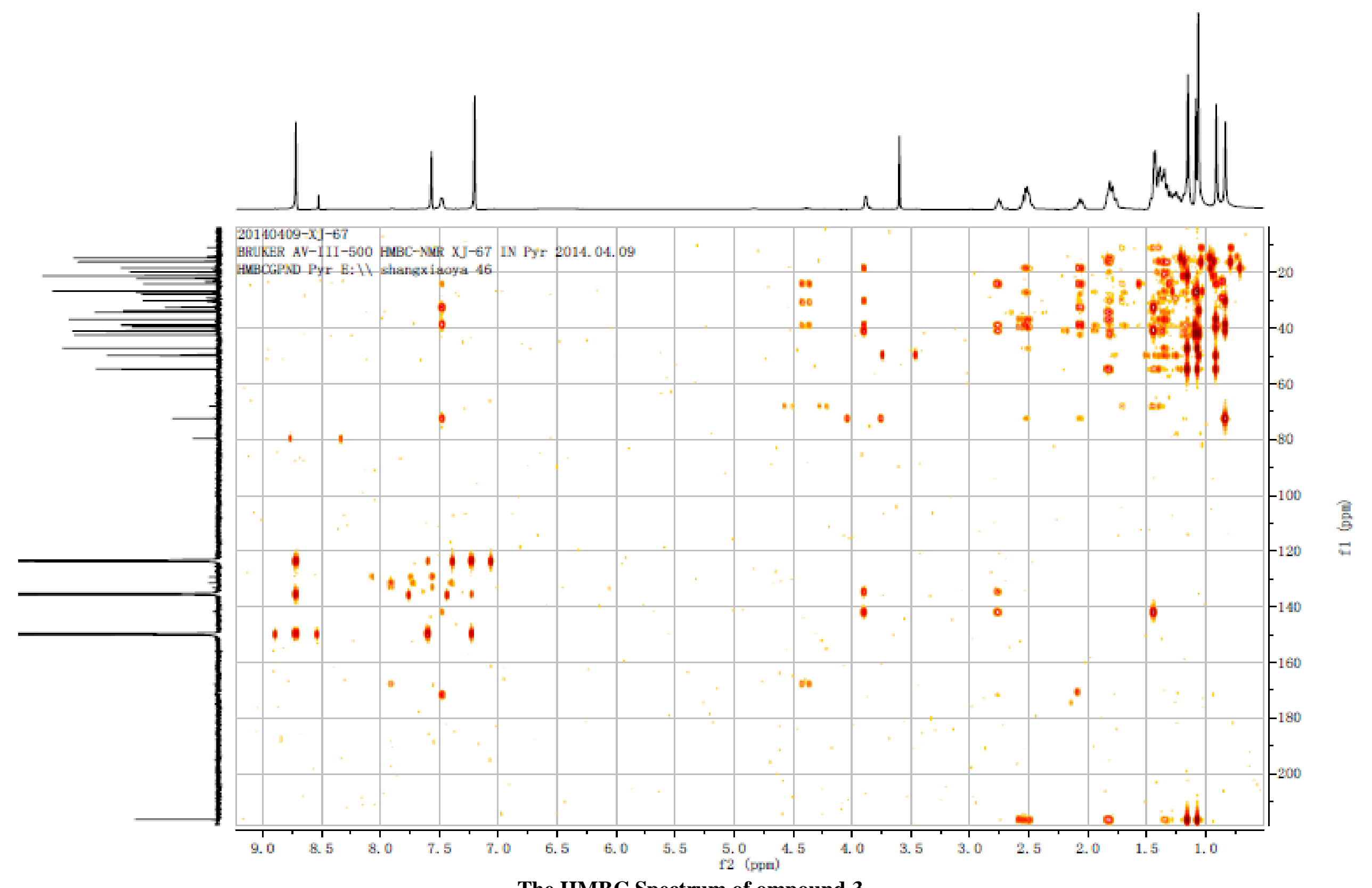

The HMBC Spectrum of ompound 3 


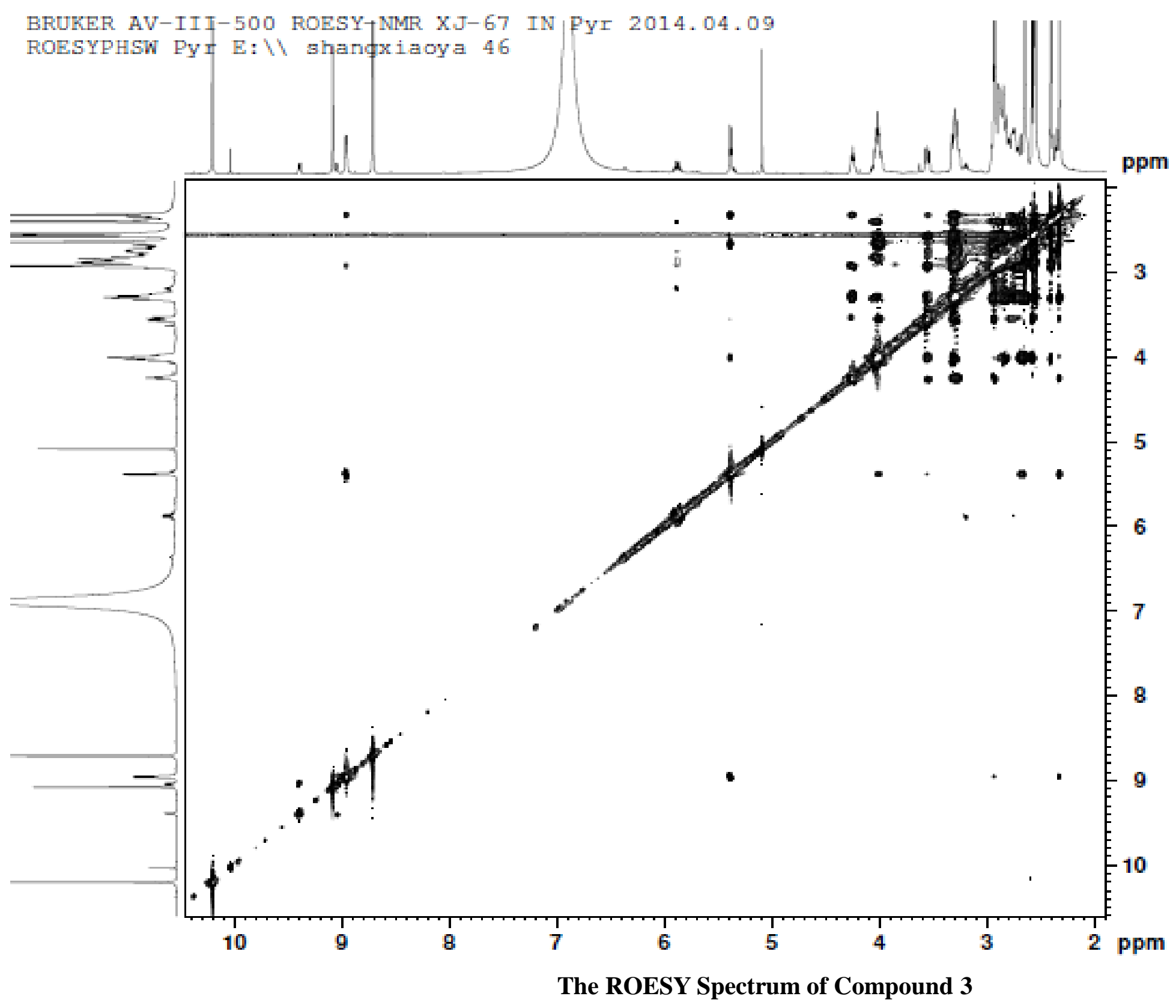

erergen

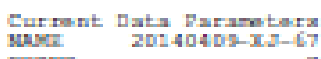

Thom
Thock

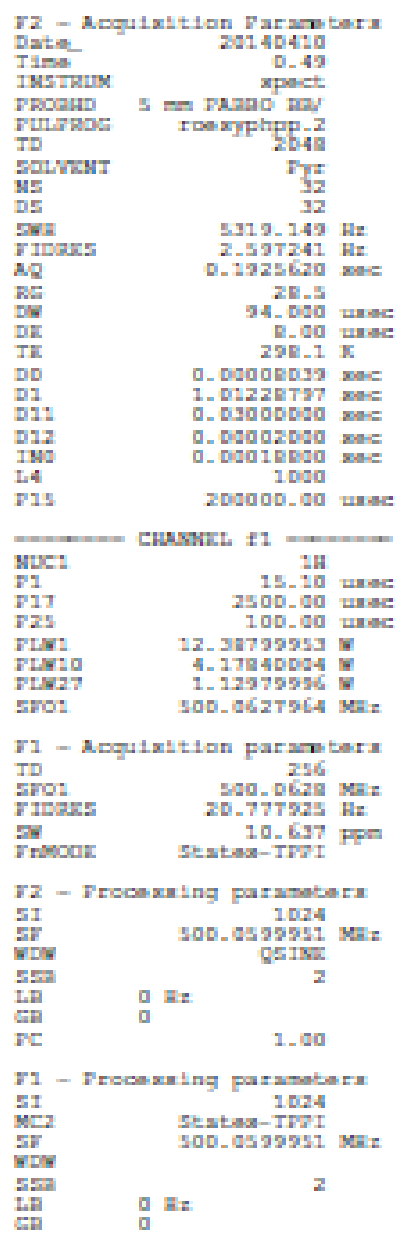




\section{Single Mass Analysis (displaying only valid results)}

Tolerance $=10.0$ PPM / DBE: $\min =-2.0, \max =40.0$

Selected filters: None

\section{Monoisotopic Mass, Odd and Even Electron Ions}

32 formula(e) evaluated with 1 results within limits (up to 50 best isotopic matches for each mass)

Elements Used:

$\begin{array}{lll}\text { C: } 0-500 & \text { H: } 0-1000 & 0: 0-4\end{array}$

Autospec
XJ-61-HREI $26(1.388) \mathrm{Cn}(\mathrm{Cen}, 5,30.00, \mathrm{Ht}) ; \mathrm{Sm}(\mathrm{Mn}, 2 \times 3.00) ; \mathrm{Cm}(25: 27)$
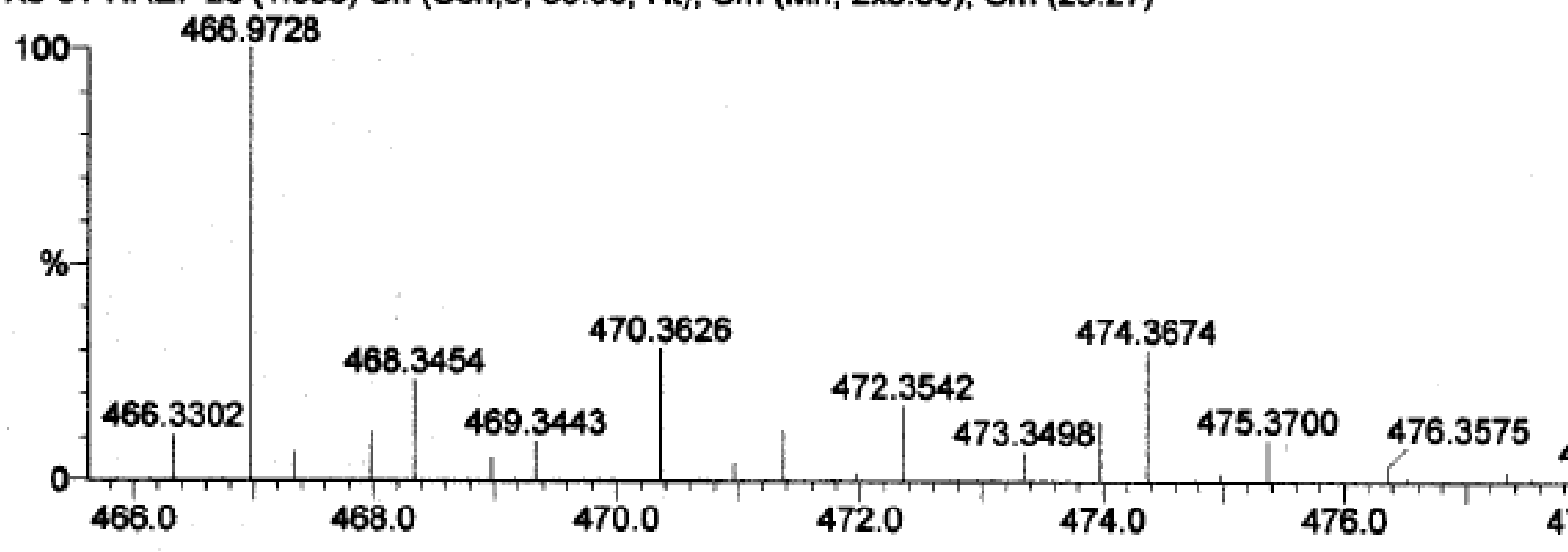

Minimum:

Maximum:
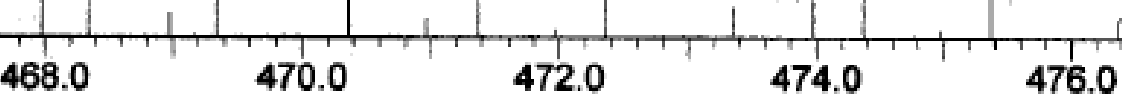

$\begin{array}{lll}5.0 & 10.0 & -2.0 \\ \text { mDa } & \text { PPM } & \text { DBE } \\ -1.1 & -2.3 & 7.0\end{array}$

The HRESIMS Spectrum of Compound 4 


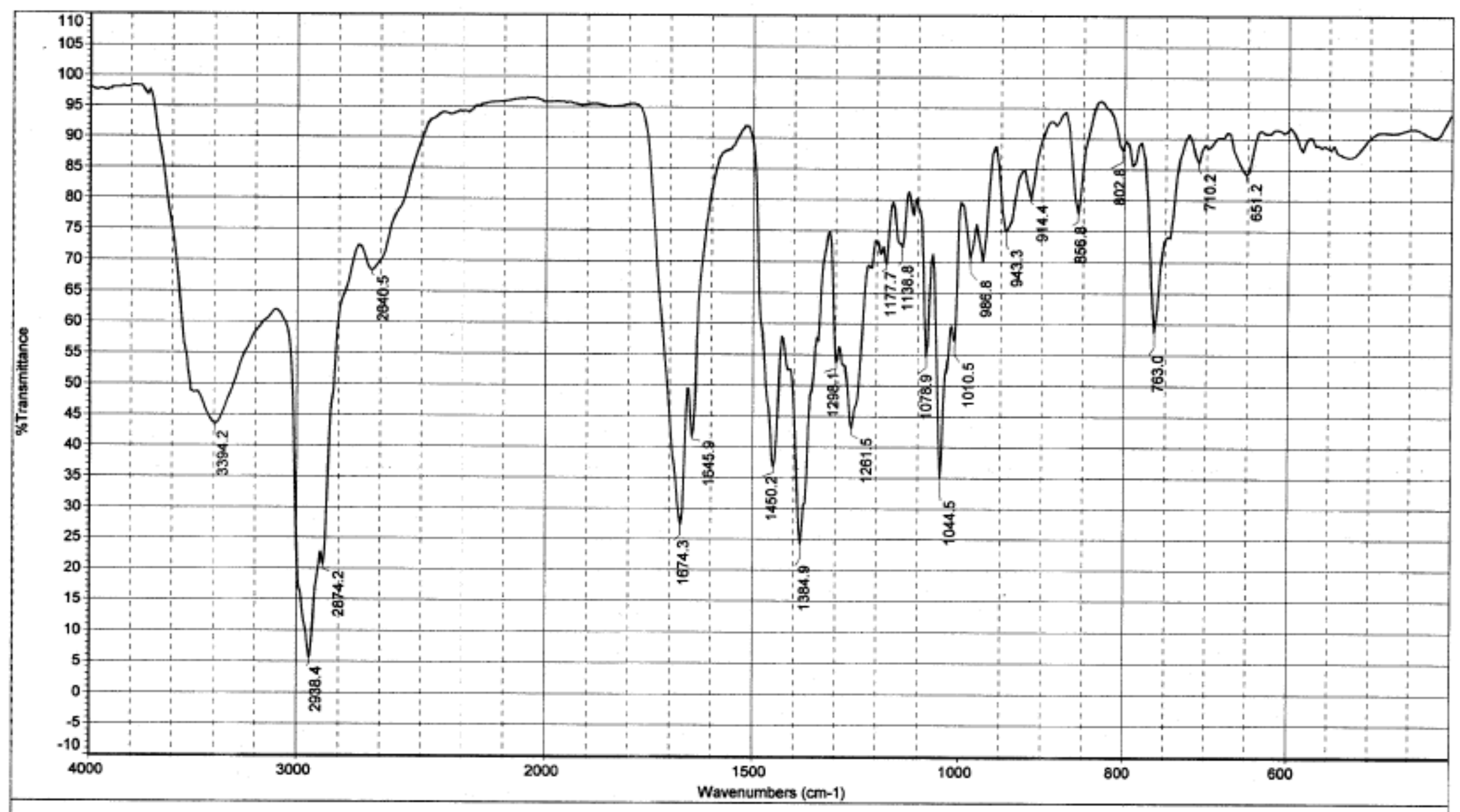

日期: 星期四 2月 27 16:29:06 2014 (GMT+08:0Sample Name: XJ - 61

(最徽镜透射法 FT- IR Microscope Transmission)

扫描次数: 100

傅里叶变换显微镜红外(FT-IR Microscope): Centaurus

分辨率: 8.000

美国热电公司(Thermo)傅里叶变换红外光谱仪:Nicolet 5700

The IR Spectrum of Compound 4 


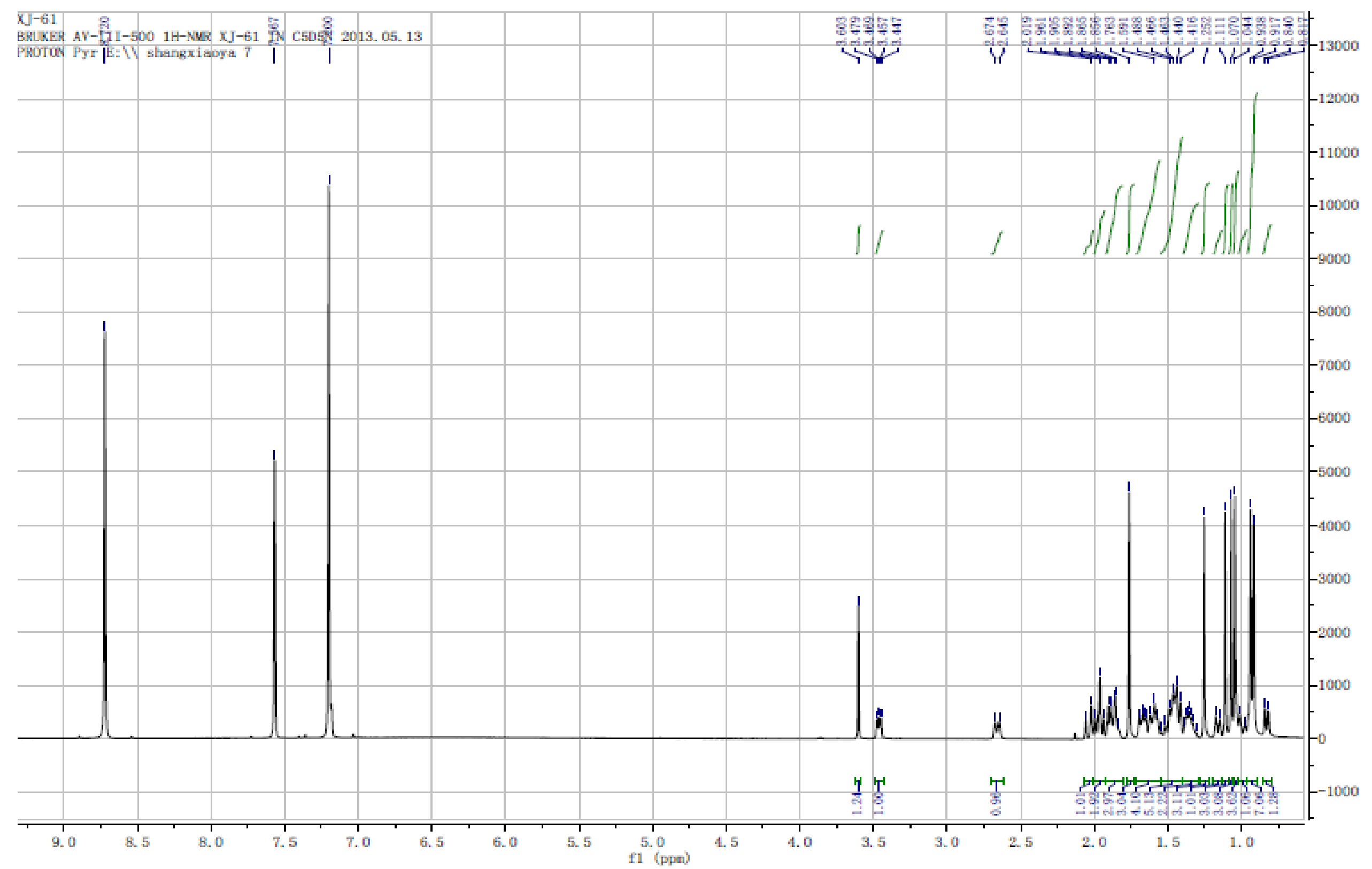

The ${ }^{1} \mathrm{H}$ NMR Spectrum of Compound 4 


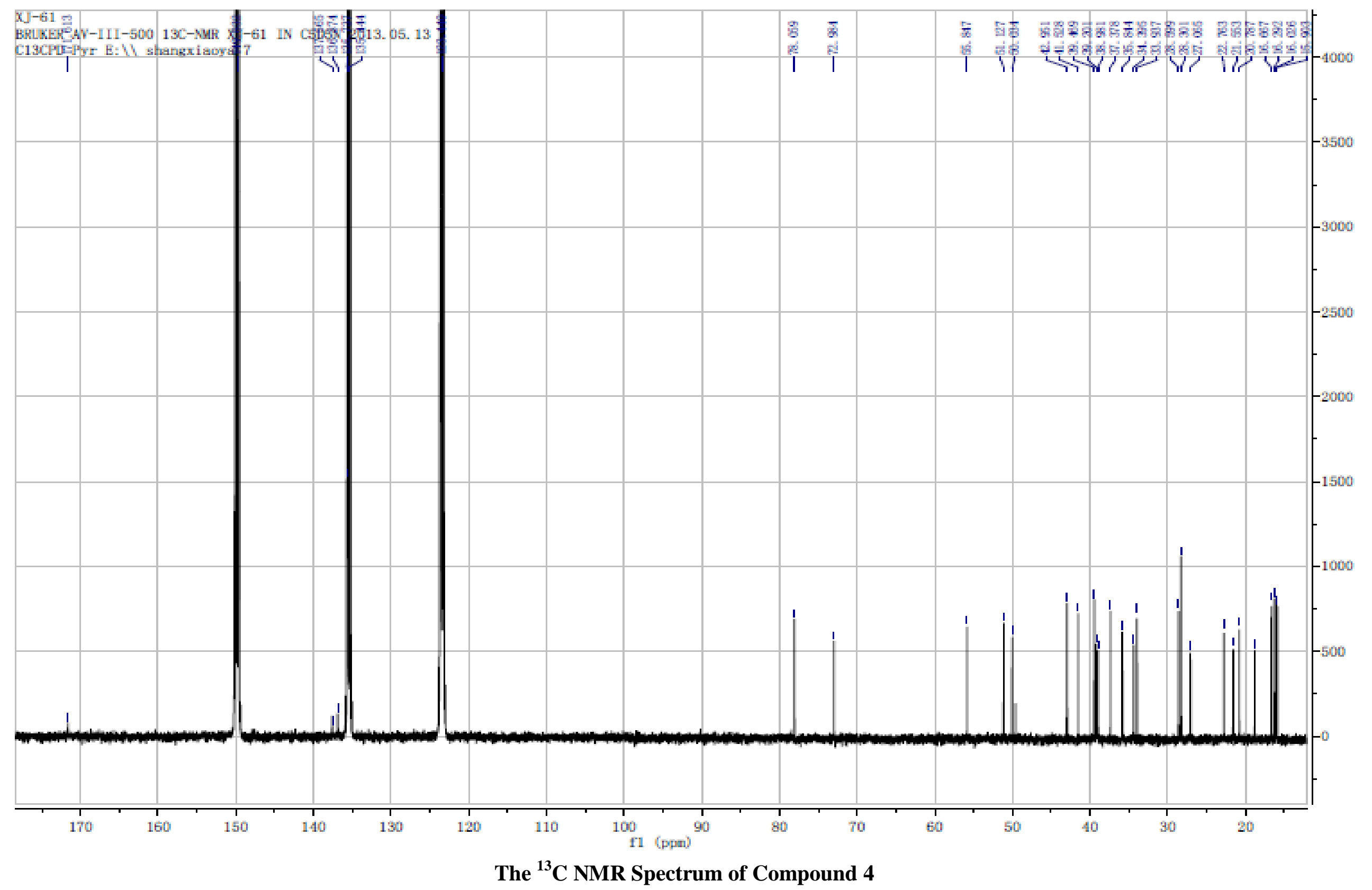

S37 


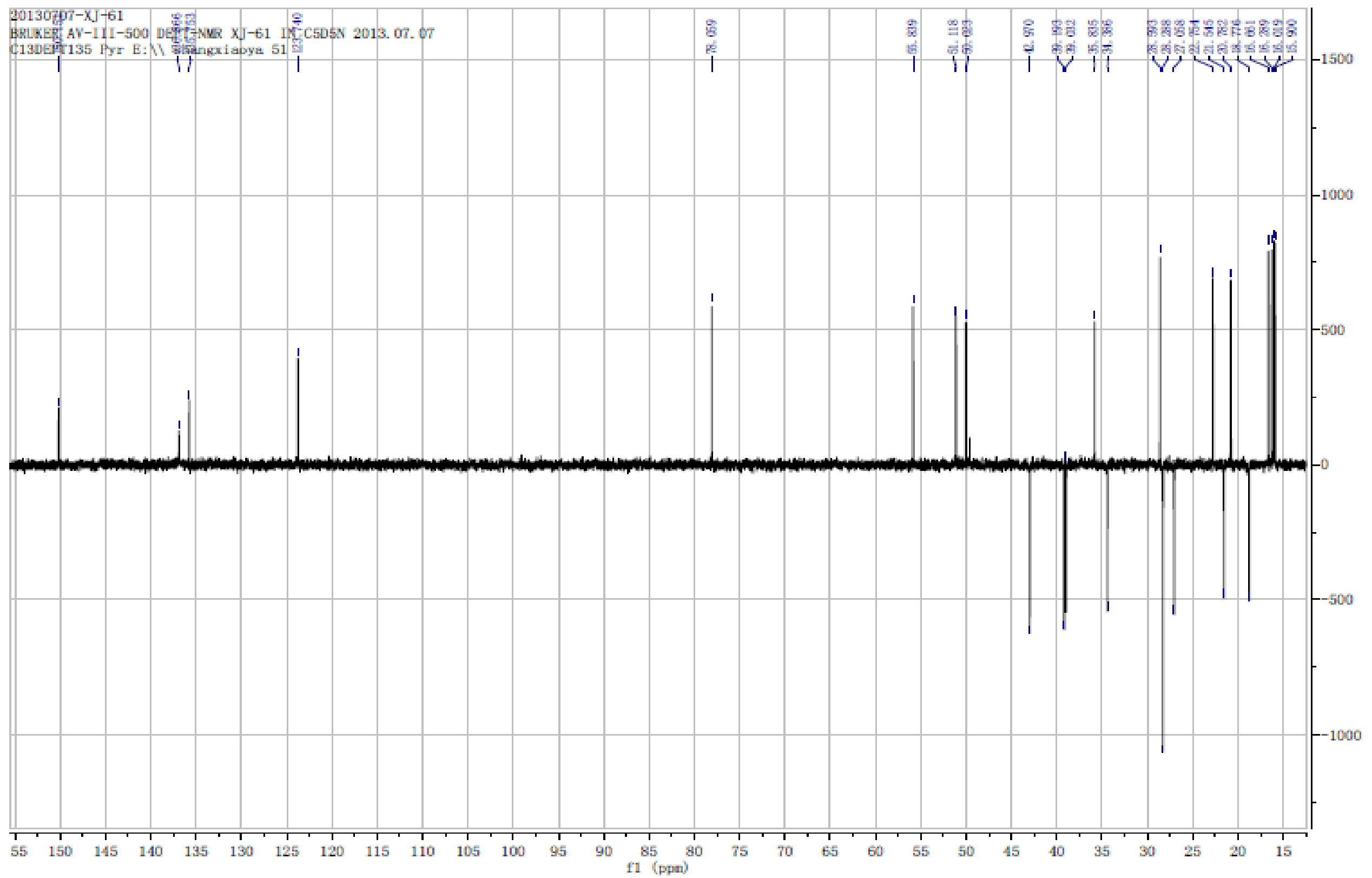

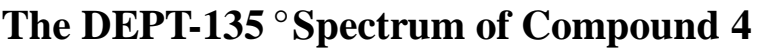




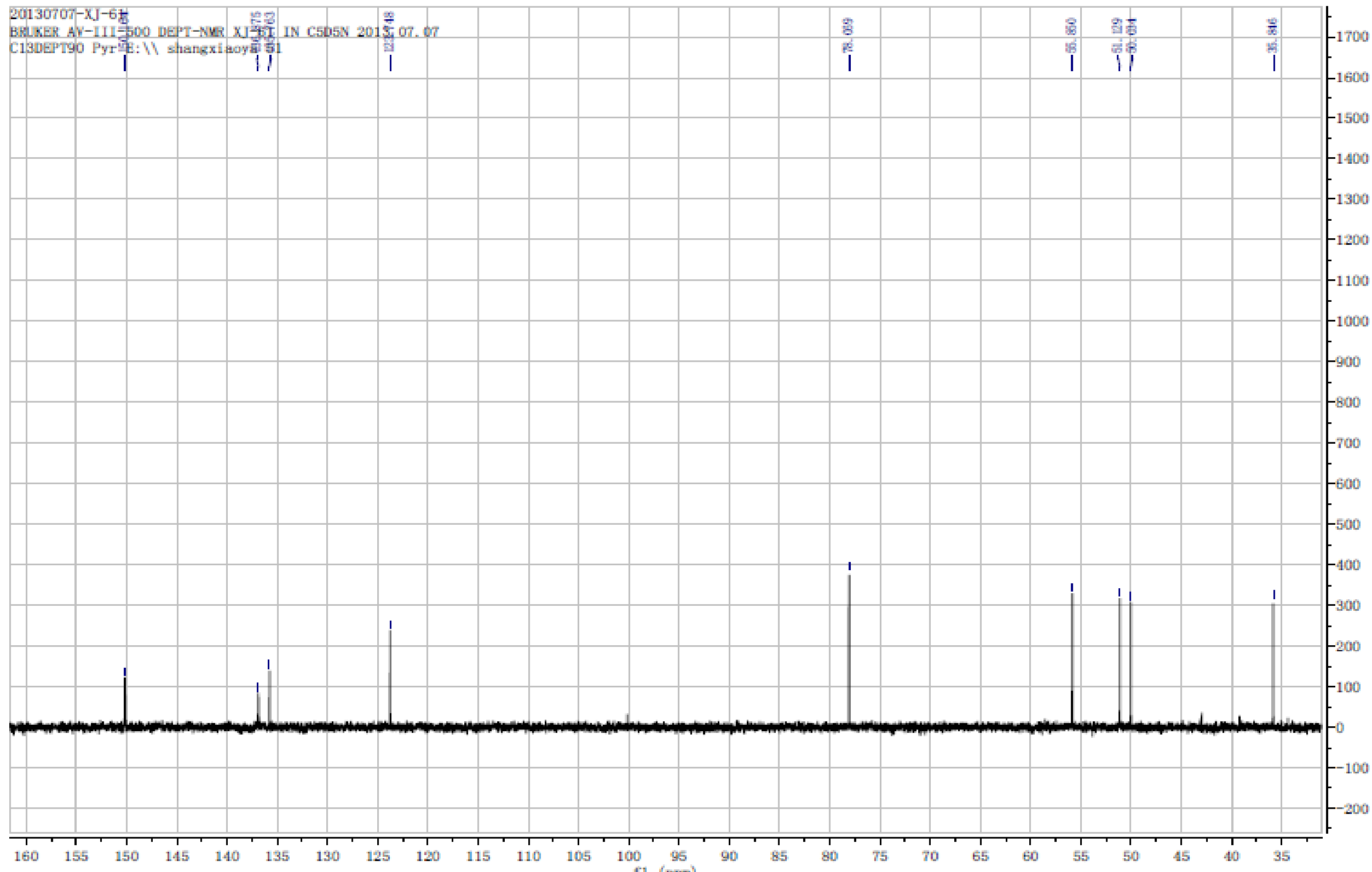

The DEPT-90 ${ }^{\circ}$ Spectrum of Compound 4

S39 


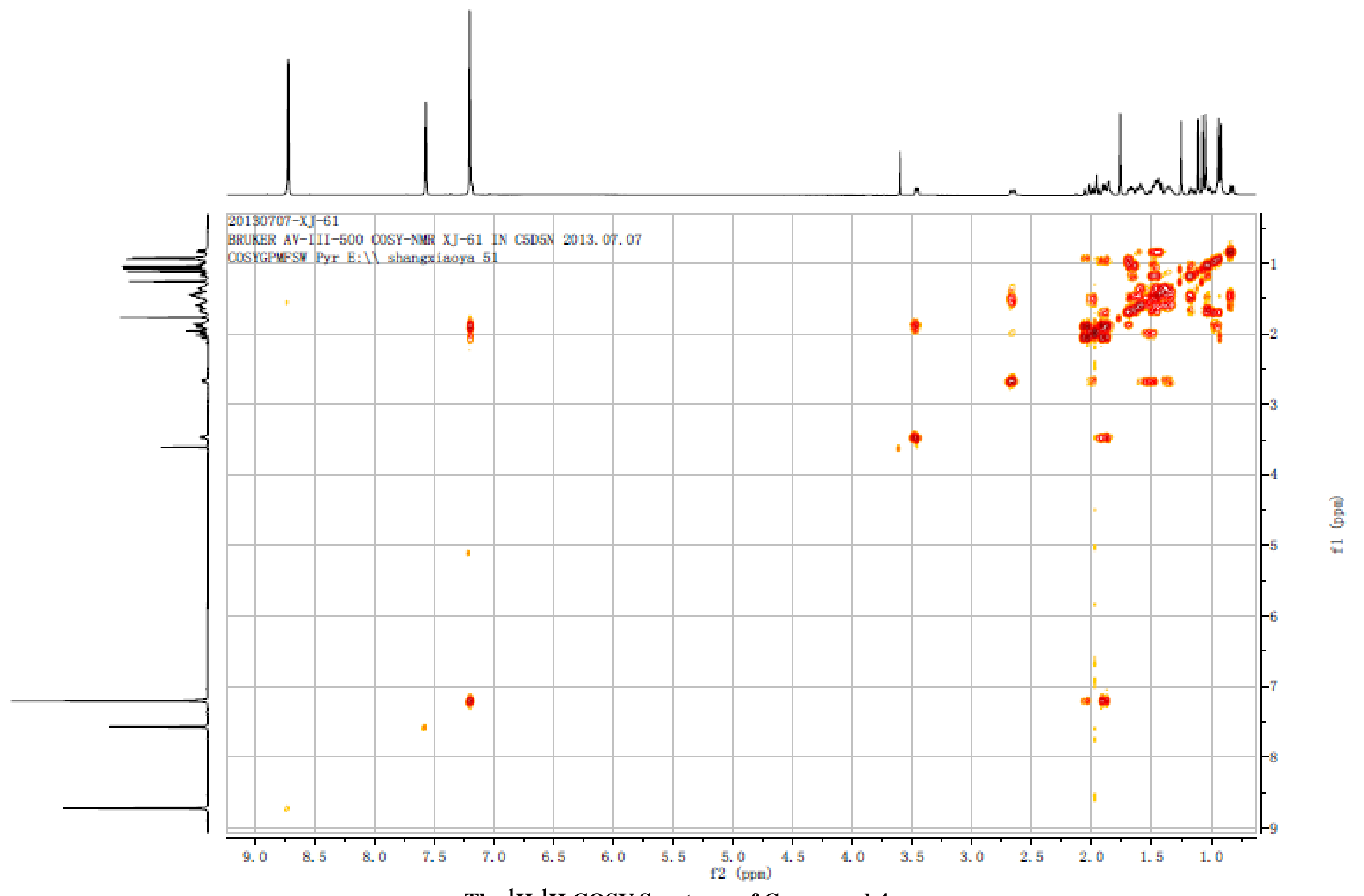

The ${ }^{1} \mathrm{H}-{ }^{1} \mathrm{H}$ COSY Spectrum of Compound 4

$$
\text { S40 }
$$




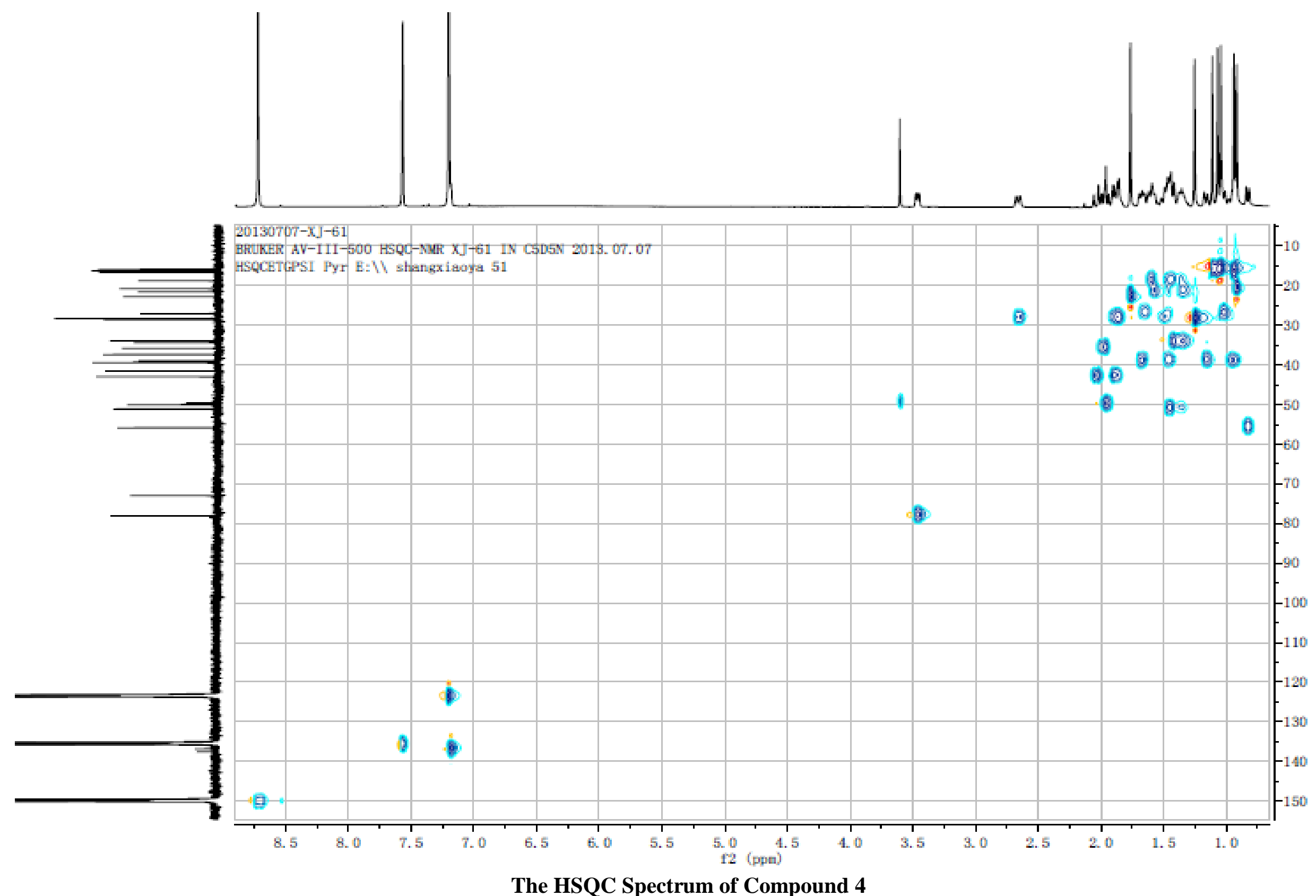




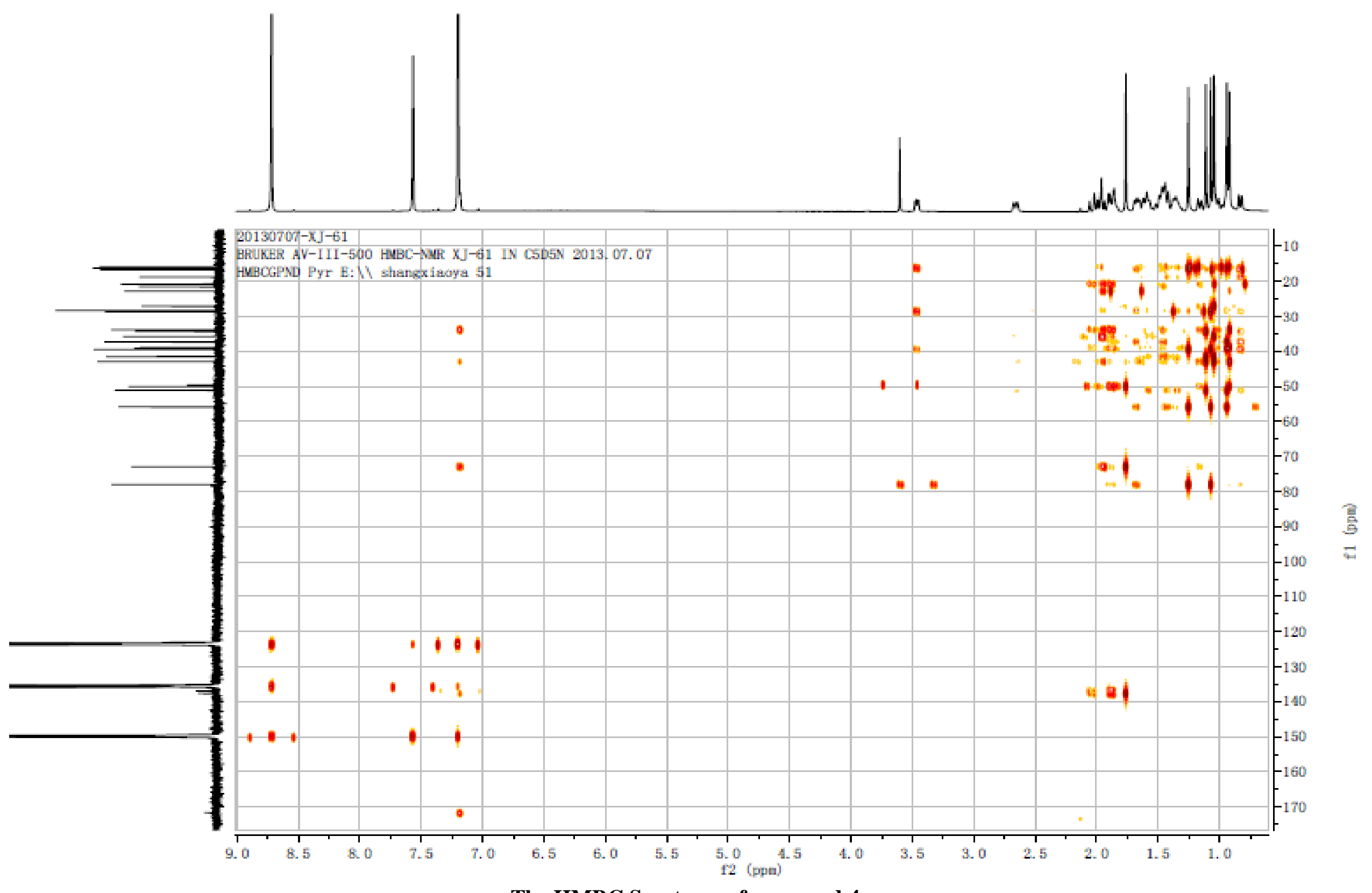

The HMBC Spectrum of ompound 4 
BRUKER AV-III-500 ROESY-NMR XJ-61 IN C5D5N 2013.07.07

ROESYPHSW PyI E: $\backslash$ shangxiaoya 51

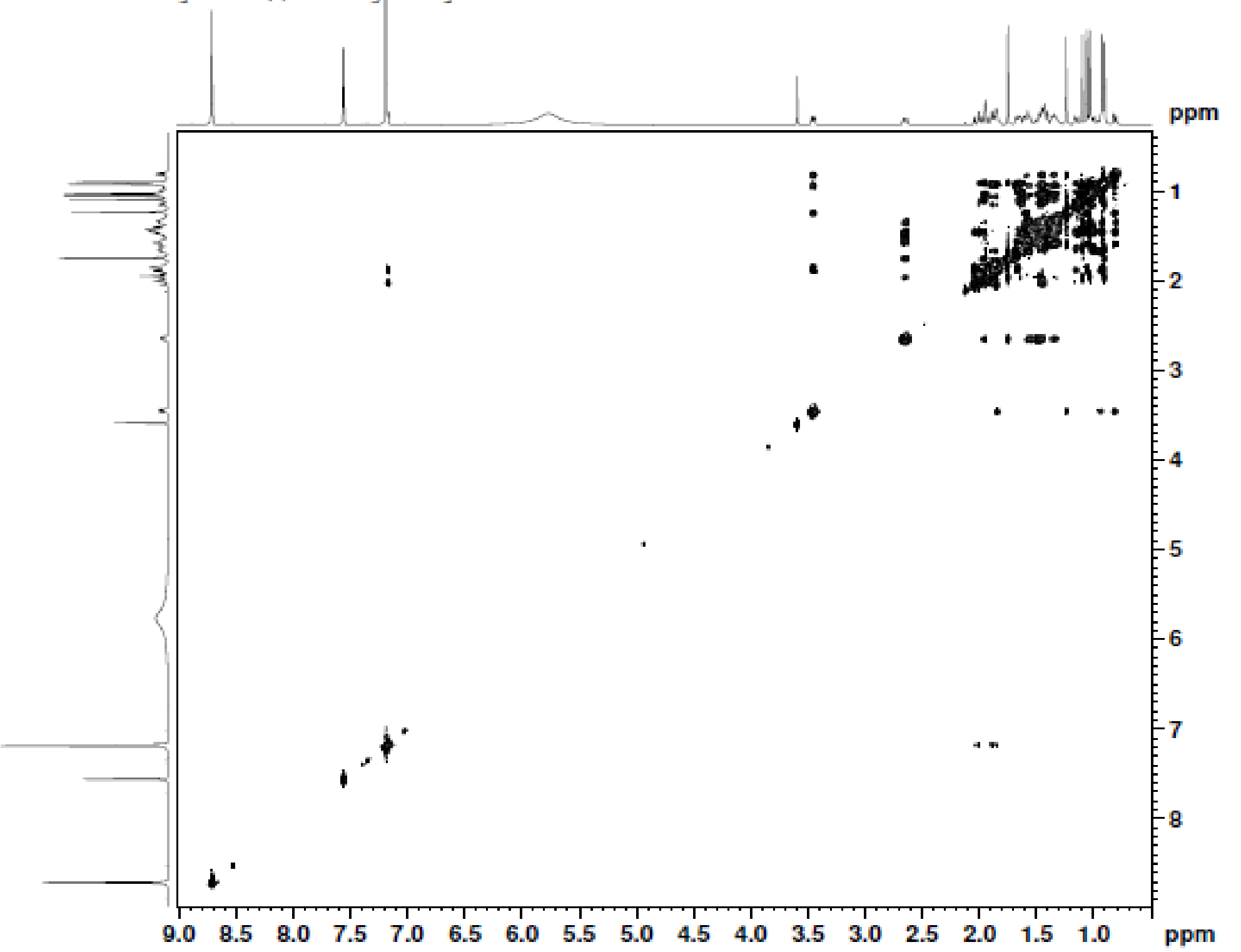

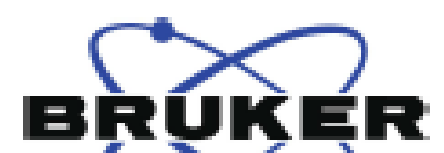
$(>>)$

Curnent Data Varameterz
wayk

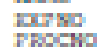

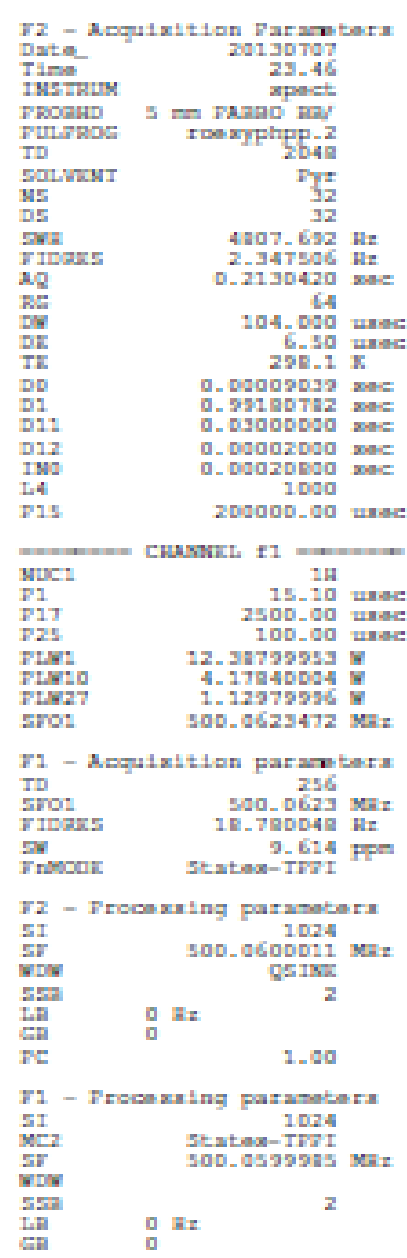

The ROESY Spectrum of Compound 4 